This item was submitted to Loughborough's Research Repository by the author.

Items in Figshare are protected by copyright, with all rights reserved, unless otherwise indicated.

\title{
Fatigue reliability and service life prediction of aluminum naval ship details based on monitoring data
}

PLEASE CITE THE PUBLISHED VERSION

http://dx.doi.org/10.1177/1475921714546059

PUBLISHER

(c) Sage

VERSION

AM (Accepted Manuscript)

\section{PUBLISHER STATEMENT}

This work is made available according to the conditions of the Creative Commons Attribution-NonCommercialNoDerivatives 4.0 International (CC BY-NC-ND 4.0) licence. Full details of this licence are available at: https://creativecommons.org/licenses/by-nc-nd/4.0/

\section{LICENCE}

CC BY-NC-ND 4.0

\section{REPOSITORY RECORD}

Soliman, Mohamed, Giorgio Barone, and Dan M. Frangopol. 2019. "Fatigue Reliability and Service Life Prediction of Aluminum Naval Ship Details Based on Monitoring Data". figshare.

https://hdl.handle.net/2134/16758. 


\title{
Fatigue Reliability and Service Life Prediction of Aluminum Naval Ship Details Based on Monitoring Data
}

\author{
Mohamed Soliman $^{1}$, Giorgio Barone ${ }^{2}$, and Dan M. Frangopol ${ }^{3, *}$
}

\section{ABSTRACT}

The evolution of naval vessels towards high-speed crafts subjected to severe sea conditions has promoted an increasing interest in lightweight high-strength materials. Due to its strength and weight characteristics, aluminum has been proven especially suitable as construction material for hull structures, as well as other vessel parts. However, fatigue in aluminum naval crafts needs to be effectively addressed for the proper life-cycle assessment. Structural health monitoring (SHM) systems constitute effective tools for measuring the structural response and assessing the structural performance under actual operational conditions. In this paper, an approach for using SHM information in the fatigue reliability analysis and service life prediction of aluminum naval vessels is presented. The accumulated fatigue damage and the fatigue reliability are quantified based on SHM data acquired under different operational conditions, specified by the ship speeds, sea states, and heading angles. Additionally, an approach for estimating the reliability-based fatigue life under a given operational profile is presented. Seakeeping trial data of an aluminum high-speed naval vessel are used to illustrate the proposed approach.

Keyword: fatigue, structural health monitoring, aluminum naval vessel, reliability, service life prediction

\footnotetext{
${ }^{1}$ Graduate Research Assistant, Department of Civil and Environmental Engineering, ATLSS Engineering Research Center, Lehigh University, 117 ATLSS Dr., Bethlehem, PA 18015-4729, mos209@,lehigh.edu

${ }^{2}$ Research Associate, Department of Civil and Environmental Engineering, ATLSS Engineering Research Center, Lehigh University, 117 ATLSS Dr., Bethlehem, PA 18015-4729, gib212@1ehigh.edu

${ }^{3}$ Professor and the Fazlur R. Khan Endowed Chair of Structural Engineering and Architecture, Department of Civil and Environmental Engineering, ATLSS Engineering Research Center, Lehigh University, 117 ATLSS Dr., Bethlehem, PA 18015-4729, dan.frangopol@lehigh.edu.

*Corresponding Author, dan.frangopol@lehigh.edu.
} 


\section{INTRODUCTION}

The use of aluminum in modern naval ships has been recently growing. This is due to its competitive weight and strength characteristics which make it preferable, over conventional steel, to comply with the rapid increase in speed and load requirements. Recently, researchers and designers have been investigating various properties of aluminum as a construction material, including the ultimate carrying capacity of stiffened panels, corrosion resistance, and fatigue behavior of aluminum details. Additionally, this material has been used for innovative structural details whose behavior may still not be well understood. As a result, methodologies for predicting aluminum ship behavior are still topics of active research, focusing especially on the hull capacity, performance in aggressive environments and fatigue resistance [1].

Fatigue damage is one of the main concerns in naval engineering. It occurs at different locations of the ship structure, where stress concentrations or fabrication defects may exist. Fluctuations of stress levels during regular ship operations may cause crack initiation and propagation at these locations. The resulting reduction of the capacity of the affected region may cause failure at load levels well below the service ones [2]. As a result, structures subjected to fatigue accumulation require frequent inspections and maintenance actions which can significantly raise the operational cost of the vessel. Fatigue assessment of steel ships and their life-cycle fatigue behavior have been widely investigated $[3,4]$, and several established design guides and technical reports have been produced [5-8]. For aluminum structures, various design guides provide rules for the fatigue design and assessment of structural details, such as the Eurocode 9 [9] and the DNV [10]. However, design guidance for fatigue life estimation in high speed naval vessels is still lacking the level of support and detail present in steel ships, and many of the structural details adopted in aluminum ships are still not included in the design codes [11]. 
Even for steel ships designed using the appropriate S-N specifications, cracks commonly initiate and propagate long before the anticipated fatigue service life is reached [12]. This suggests the need for additional research and refinements in the current fatigue design and assessment approaches to accurately understand the actual ship fatigue behavior under normal operational conditions.

Structural performance prediction of ships under sea loading is subjected to uncertainties inherent in the load conditions, material properties, damage propagation and cross-sectional dimensions. In this context, structural health monitoring (SHM) is an important tool for the reduction of uncertainties, providing information on the real-time structural response [13]. For fatigue studies, SHM data can be used for calculating the fluctuating stress levels acting on the details at different operational conditions. This task could be theoretically performed through a comprehensive finite element analysis (FEA) coupled with spectral analysis of the actual ship properties [14]. However, this process is more suited towards the design stage as it consists of significant assumptions and simplifications that can be dropped by using SHM.

Reliability analysis provides a unified measure of the structural performance that takes into account both aleatory and epistemic uncertainties [15], an attractive feature for fatigue analysis. Moreover, it can give an adjusted service life based on the required reliability level of the ship, which is a function of the ship importance, age, and use, among others [16]. Although reliability-based fatigue evaluation of steel ship details is well established (see $[3,4])$, it is still an active research area for aluminum ones. Most of the studies in this field predict the unified longterm probability density function (PDF) of the ship loading based on the anticipated ship operational conditions which assumes a specific combination of speeds, heading angles, and wave conditions [12,17-19]. This adds significant uncertainties in the fatigue life estimation 
especially for littoral combat vessels which do not have a well-defined route and are required to operate in a wide range of operational conditions $[12,20]$. Additionally, this approach leaves no room to investigate the effect of different operational conditions on the fatigue damage accumulation. As a result, it is not possible to isolate those operational conditions causing severe fatigue damage from the ship operational profile. This operational profile, developed based on the operational conditions encountered by the ship, is defined in the form of discretized blocks of constant sea-state, speed, and relative heading. Each block has an associated probability representing the fraction of the navigation time spent in that operational condition [17]. However, this load profile cannot be easily updated if the ship operational profile changes at any point during its life-cycle.

This article presents a reliability-based approach to quantify the long-term reliability and fatigue service life of naval ships based on the short-term SHM data collected during seakeeping trials. The fatigue reliability and damage accumulation are assessed with respect to various operational conditions, including the significant wave height, encountered wave period, navigation speed, and heading angle. The effect of automated ride control systems at various operational conditions on the fatigue performance and reliability is also investigated. The results can be effectively integrated within the life-cycle management framework to support the decision making process with regards to the safe operational conditions. Moreover, it can assist in the evaluation of the current design and assessment guidelines under the effect of large number of cycles that are normally not reached in laboratory testing. Additionally, a computationally efficient approach for the reliability-based estimation of the fatigue service life, based on the SHM data collected either during seakeeping trials or normal ship operation, is proposed. After the initial data analysis, the proposed approach allows non-technical crew personnel to estimate 
the remaining fatigue life at critical details. The approach is applied to the SHM data collected during seakeeping trials performed on an aluminum high-speed naval vessel (the HSV-2) in 2004.

\section{FATIGUE DAMAGE}

Fatigue assessment can be typically performed using the S-N (i.e., stress-life) or the crack growth method [21]. The S-N approach, adopted in this paper, provides a relationship (usually, linear or bilinear) between the logarithm of the stress range and the logarithm of the expected number of cycles to failure for several typologies of details (see Fig. 1). The crack growth approach, on the other hand, provides theoretical methods to predict propagation of cracks as a function of several variables including the stress range, number of cycles, and geometry, among others, and, therefore, leading to the identification of the fatigue life of the detail [22]. It provides more detailed analysis with a wider range of applications, but requires considerably more computational effort than the S-N approach. For this reason, the S-N approach is adopted by the majority of the design guides and specifications.

As previously mentioned, fatigue is considered as a major threat for metallic structures in general, and for ships in particular, since the vessel is subjected to a large number of stress cycles throughout its service life. This is more endangering in the case of aluminum high-speed vessels. Despite their competitive corrosion resistance and strength to weight ratio, aluminum structures have a crack propagation rate considerably higher than steel structures [1], and therefore a shorter expected fatigue life. This is clearly represented in Fig. 1 where the S-N diagrams of the same details made of aluminum and steel are compared. These S-N lines are adapted from the Eurocode 3 [23] and the Eurocode 9 [9] for steel and aluminum constructions, respectively. Fig. 1-(a) depicts the S-N relations for rolled or extruded aluminum and steel members, while Fig. 1- 
(b) illustrates the same relations for a welded member. As shown, for any stress level, the fatigue life of the aluminum members is considerably lower than that of steel members compared to the steel ones, and the difference is significantly larger in the case of welded structures.

For the linear S-N relationship, the number of cycles to failure $N$ within a detail is calculated as

$$
N=\frac{A}{S^{m}}
$$

where $A$ is the fatigue coefficient dependent on the type of the detail, $m$ is the slope of the S-N lines in logarithmic scale, and $S$ is the stress acting on the detail.

\section{Stress range}

Different stress analysis methods can be used for the fatigue assessment of aluminum details, namely the nominal stress, structural hot spot stress, and notch stress $[24,25]$. The choice of the stress type and its corresponding S-N relationships mainly depends on the available data. The nominal stress approach is adopted by several design and assessment guides such as the Eurocode 9 [9]. This method uses the stress acting on the considered location neglecting the stress concentration arising from both the structural configuration and the weld effect. These effects are inherently considered within the S-N line definition. The main advantage of using this approach is the ease of application since the nominal stress calculation is usually straightforward. On the other hand, to assess the fatigue damage for a specific detail using this approach, a similar match in the design guide has to be found, and this is not always possible for ship structures.

The structural hot spot stress approach uses the stress induced in the proximity of the weld, including the stress concentration due to the structural configuration but not due to the 
weld itself. This stress is next compared to S-N lines which, instead, incorporate the effect of weld stress concentration. The calculation of the structural stress requires more advanced structural analysis than the nominal stress case. To exclude the stress concentration due to the weld, a single reference point at a prescribed distance from the weld toe can be used; otherwise the structural stress can be extrapolated by measurements performed at multiple reference points [26]. The advantage of such approach is that a lower number of S-N curves needs to be evaluated compared to the nominal stress case.

The last method, the notch stress, uses the total stress acting at the crack initiation location, which includes the stress concentration due to both the structural configuration and the weld geometry. The notch stress is usually more difficult to obtain; however, it can be used to find the fatigue life of the structural detail using the S-N curve for a base non-welded metal. A representation of the three stress types is shown schematically in Fig. 2.

When dealing with SHM data, it is not practical to find the stress concentration at the weld toe using strain measurement, due to the high stress gradient at this location. Thus, depending on the available data, the nominal stress approach can be used if a similar detail can be found in design guides. Otherwise, the structural hot spot stress approach can be used. In the latter case, several recommendations for the placement of sensors to measure the structural stress can be found in literature. For instance, Niemi [27] proposes to perform linear extrapolation of the stresses identified at distances $0.4 t_{p}$ and $1.0 t_{p}$ from the weld toe, where $t_{p}$ is the plate thickness. Other classification societies, such as the Lloyd's Register whose approach is adopted herein, use the stress measured at $0.5 t$ as the structural stress [24].

\section{Equivalent Constant Amplitude Stress Range}


Ship structures are naturally subjected to variable amplitude stress cycles. If the distribution of the stress cycle amplitudes is known, Miner's damage accumulation rule [28] can be used to find a representative equivalent constant amplitude stress range. By considering the stress cycle amplitude histogram, and under the assumption of linear damage accumulation, Miner's damage accumulation index $D$ is the defined as

$$
D=\sum_{i=1}^{n_{s s}} \frac{n_{i}}{N_{i}}
$$

where $n_{s s}$ is the number of stress range bins in a stress-range histogram, $n_{i}$ is the number of stress cycles in the $i$ th bin with stress range $S_{i}$ and $N_{i}$ is the number of cycles to failure under the stress range $S_{i}$. According to Miner's damage accumulation rule, the failure of the detail occurs when $D$ $=1.0$. However, research showed that this value is subjected to various uncertainties, and up to date, no value is accepted by all research communities [4]. It should also be noted that other models for predicting fatigue damage accumulation exist. These models can consider additional phenomenological factors such as the load sequence and overload effects. However, due to its simplicity and agreement with test data, Miner's damage accumulation rule is still adopted by most of the fatigue design and assessment guidelines [29].

Based on Miner's damage accumulation rule, an equivalent constant amplitude stress range can be defined as [4]

$$
S_{r e}=\left[\sum_{i=1}^{n_{s s}} \frac{n_{i}}{N_{T}} \cdot S_{i}^{m}\right]^{\frac{1}{m}}
$$


where $N_{T}=\sum_{i=1}^{n_{s s}} n_{i}$. Alternatively, $S_{r e}$ can be calculated using the probability density function $f_{S}(s)$ of the stress range $S$ as follows

$$
S_{r e}=\left[\int_{0}^{\infty} s^{m} \cdot f_{S}(s) \cdot d s\right]^{\frac{1}{m}}
$$

For the case study discussed in this paper, it was found that the Weibull distribution provides a very good fit for the stress range data of the analyzed aluminum detail. The threeparameter PDF of this distribution is expressed as

$$
f_{S}(s)=\frac{\kappa}{\alpha} \cdot\left(\frac{s-s_{c}}{\alpha}\right)^{\kappa-1} \cdot \exp \left[-\left(\frac{s-s_{c}}{\alpha}\right)^{\kappa}\right]
$$

where $s>s_{c}$ and $\alpha$ and $\kappa$ are the scale and shape parameters of the Weibull distribution, respectively. The cut-off threshold $s_{c}$ is the lowest stress level considered in the stress range bin histogram [30]. In many cases, depending on the stress range bin histogram, a two-parameter PDF can be used considering $s_{c}=0$.

\section{Fatigue Life}

For an equivalent constant amplitude stress range, fatigue life can be measured by the number of cycles to failure using Eq. (1). This number of cycles $N$, in conjunction with the average annual number of cycles $N_{\text {avg }}$ obtained by the SHM data, returns an estimation of the fatigue life $t_{f}$ in years, using the following equation

$$
t_{f}=\frac{N}{N_{a v g}}
$$


and, therefore, the remaining fatigue life $T_{r e m}$ is

$$
T_{r e m}=t_{f}-t_{s}
$$

where $t_{\mathrm{s}}$ is the already spent service life.

\section{Fatigue Reliability}

The reliability index $\beta$ has been widely accepted as a structural performance measure. It is directly linked to the probability of failure $P_{f}$ (i.e. the probability of violating a certain limit state), through the following relationship [30]

$$
\beta=\Phi^{-1}\left(1-P_{f}\right)
$$

in which $\Phi^{-1}(\cdot)$ is the inverse of the standard normal cumulative distribution function.

For the probabilistic assessment of the remaining fatigue life, a reliability approach can be used based on the definition of the following performance function

$$
g(t)=\Delta-D(t)
$$

where $\Delta$ is Miner's critical damage accumulation index, indicating the allowable accumulated damage and assumed lognormal distributed with mean 1.0 and coefficient of variation (COV) 0.48 [19]; $D(t)$ is Miner's damage accumulation index, which can be expressed as

$$
D(t)=\frac{N(t)}{A} \cdot S_{r e}^{m}=\frac{t \cdot N_{a v g}}{A} \cdot S_{r e}^{m}
$$

where $A$ and $m$ are S-N relationship parameters (see Eq. 1), $S_{r e}$ is the equivalent constant amplitude stress range (see Eqs. 3 and 4), and $N_{\text {avg }}$ is the average annual number of cycles. 
Based on Eqs. (9) and (10) and assuming that all the random variables (i.e. $S_{r e}, A$, and $\Delta$ ) follow the lognormal distribution [4,30], the fatigue reliability index $\beta$ can be derived as follows:

$$
\beta(t)=\frac{\lambda_{\Delta}+\lambda_{A}-m \cdot \lambda_{S_{r e}}-\ln N(t)}{\sqrt{\zeta_{\Delta}^{2}+\zeta_{A}^{2}+\left(m \cdot \zeta_{S_{r e}}\right)^{2}}}
$$

where $\lambda$ and $\zeta$ are the lognormal parameters associated with different random variables.

Eqs. (9) and (10) can be used to evaluate the reliability index using computer software such as RELSYS [31] or CalREL [32]. Alternatively, Eq. (11) can be used directly to calculate the time-variant reliability index under the assumption that all the random variables have a lognormal PDF. By setting a fatigue reliability threshold $\beta_{\text {target }}$ and considering Eq. (11), the fatigue life $t_{f}$ can be determined as follows

$$
t_{f}=\frac{e^{k-m \cdot \lambda_{S_{r e}}}}{N_{a v g}}
$$

where

$$
k=\lambda_{\Delta}+\lambda_{A}-\beta_{\text {target }} \cdot \sqrt{\zeta^{2}}
$$

and

$$
\zeta^{2}=\zeta_{\Delta}^{2}+\zeta_{A}^{2}+\left(m \cdot \zeta_{S_{r e}}\right)^{2}
$$

Eq. (12) represents an immediate way to estimate the reliability-based fatigue life for a selected operational condition, once the associate stress range distribution is known. 


\section{FATIGUE RELIABILITY UNDER MULTIPLE OPERATIONAL CONDITIONS}

Investigating the long-term fatigue reliability of a ship detail requires analyzing all operating conditions that the vessel is expected to encounter. The main factors that have to be taken into account are ship speed, wave height and period, and heading angle. Long-term fatigue assessment of high-speed vessels can be performed using the lifetime weighted sea method [33]. This method predicts the ship long-term response as a combination of short term structural responses evaluated for various operational conditions. In this type of analysis, the response is usually obtained by structural analysis. Stress transfer functions, determined at the studied location for the specified ranges of wave heights and periods and heading angles, are used to calculate the stress energy spectrum and the spectral moments. The short-term responses are combined into a long-term one, for a prescribed operational profile, through the probabilities of the different short-term operational conditions. Moreover, under the assumption of Gaussian distributed loads and narrow-band load response, closed form solutions are available for the determination of the cumulative damage accumulation [5,34]. As mentioned previously, this process is based on significant assumptions that are not always realistic for high-speed naval vessels and may be avoided by using the SHM data.

When SHM is available, the short-term response of the ship detail, for a selected operational condition, can be directly found using strain measurements recorded during seakeeping trials, performed on the vessel at the beginning of its service life. Subsequently, for a prescribed operational profile with assigned probabilities of occurrence $p_{j}$ of different sea states, speeds, and heading angles, the total damage accumulation index $D_{T}$ can be found, under the assumption of linear damage accumulation, as 


$$
D_{T}=T_{r} \cdot \sum_{j=1}^{n_{o}} p_{j} \cdot D_{j}
$$

where $n_{o}$ is the number of operational conditions encountered by the ship during the reference time $T_{r}$ (years), and $D_{j}$ is the annual damage accumulation index for the detail associated with the $j$ th operational condition. An alternative approach to compute $D_{T}$ is to find an equivalent stress range by using Eq. (3) and calculating the total damage accumulation under this equivalent condition. Finally, the fatigue life $T_{f}$ can be found as

$$
T_{f}=\frac{T_{r}}{D_{T}}=\frac{1}{\sum_{j=1}^{n_{o}} p_{j} \cdot D_{j}}
$$

Similarly, the fatigue reliability under multiple operational conditions can be evaluated using the performance function

$$
g(t)=\Delta-D_{T}
$$

which can be expressed as

$$
g(t)=\Delta-T_{r} \cdot \sum_{j=1}^{n_{o}} p_{j} \cdot D_{j}
$$

By substituting Eq. (10) into Eq. (18), the performance function can be rewritten as

$$
g(t)=\Delta-T_{r} \cdot \sum_{j=1}^{n_{o}} p_{j} \cdot N_{a v g_{j}} \cdot \frac{S_{r e_{j}}^{m}}{A}
$$

where $N_{a v g_{j}}$ is the average number of cycles acting on the detail during one year of exposure to the $j$ th operational condition, and $S_{r e_{j}}$ is the constant equivalent stress range acting on the detail 
at the $j$ th operational condition. The stress range and the number of cycles can be found using the SHM data collected during the water trials. Eq. (19) can be used to find the time-variant fatigue reliability, and the fatigue life can be determined by comparison with a prescribed target reliability threshold.

For the case where the random variables follow the lognormal distribution, it has not been possible to determine the analytical solution of Eq. (19) in terms of the reliability index due to the presence of the sum over the different operational conditions constituting the complete operational profile. Accordingly, an approximate reliability-based fatigue life is herein proposed, based on the individual fatigue lives associated with different operational conditions. Denoting $t_{f_{j}}$ as the reliability-based fatigue life under the $j$ th operational profile, an approximate damage accumulation index $D^{*}$ can be defined for the detail after exposure to $n_{o}$ operational states, as

$$
D^{*}=T_{r} \cdot \sum_{j=1}^{n_{o}} \frac{p_{j}}{t_{f_{j}}}
$$

where $t_{f_{j}}$ can be calculated using Eqs. (12) - (14) as

$$
t_{f_{j}}=\frac{e^{k_{j}-m \cdot \lambda_{S_{r e, j}}}}{N_{a v g_{j}}}
$$

Thus, the reliability-based fatigue life $T_{f}$ is obtained as

$$
T_{f}=\frac{T_{r}}{D^{*}}=\frac{1}{\sum_{j=1}^{n_{o}} \frac{p_{j}}{t_{f_{j}}}}
$$


This approach, in which short-term monitoring data are used to predict the long-term response, offers several advantages compared to adopting either a single long-term load response or a long-term monitoring program. A unified long-term load response has the main drawback of being strongly dependent on the anticipated long-term operational profile for the ship. For high speed naval vessels, usually, a safe operational envelope can be defined to establish ship use limitations to specific sea conditions in order to reduce the likelihood of damage to the ship structure. In fact, the reaction of the crew towards the operational envelope has a significant effect on the actual long-term loading profile [11]. A change in the operational profile will alter the predicted long-term response and, as a result, the estimated fatigue life has to be recalculated. If the fatigue life estimation is required for a different operational profile, the analysis has to be entirely redone since the combination of the short-term responses constitutes the first step in the fatigue assessment. In this regards, the approximate approach proposed herein only requires to update the probabilities of occurrence $p_{j}$ for the new long-term operational profile and evaluate the reliability-based fatigue life by Eq. (22). Therefore, the assessed fatigue life can be easily updated whenever new information on the actual operational profiles of the ship is available. It is worth noting that the reliability threshold should be selected a priori by the vessel manager, and that the proposed procedure allows determining the fatigue life with respect to the selected target.

On the other hand, long-term monitoring programs are expensive due to the high cost associated with the monitoring systems, as they require regular maintenance activities and regular data processing, which may add a significant burden to the operational cost of the ship. In general, the cost of long-term monitoring program consists of the (a) general access and preparation cost, (b) monitoring system cost, (c) maintenance cost, and (d) continuous analysis 
and report preparation cost. The latter often constitutes the largest part of the monitoring program cost [35].

\section{CASE STUDY}

\section{General}

The fatigue assessment and reliability analysis presented in this paper are applied to the HSV-2 swift, an aluminum wave piercing catamaran, with an overall length of 98 meters, designed and built in Tasmania, Australia [36]. The HSV-2 is capable of reaching speeds of 38-47 knots while maintaining an average speed of 35 knots [37]. The ship is also equipped with a T-foil that is used by the ride control system to stabilize the ship motions at high speeds. A general view of the ship is shown in Fig. 3-(a) based on [20,36-38]. The ship was completed in December 2003 and it was instrumented with various types of sensors, during the period 2003-2004, to measure the (a) primary load response, (b) stress concentrations, (c) secondary slam loads, (d) ramp, crane, vehicle deck, and helicopter deck strains. Moreover, the ship was instrumented with accelerometers at various locations and an over-the-bow wave height system supplemented by Tsurumi Seiki Co. Ltd. (T.S.K) [39]. Foil strain gages as well as piezoelectric accelerometers were wired and connected to remote junction boxes and an instrumentation trailer [36]. The instrumentation required the use of remote junction boxes to provide a cabling scheme in which small sensor wires from multiple locations were combined and routed in larger cables for termination at the instrumentation trailer; a two-pair signal cable connecting the sensor to the remote junction boxes was installed by the monitoring personnel [36]. The main objectives of the monitoring plan were to (a) develop safe operating limits for the HSV-2 swift based on structural responses measured during calm water powering trials and rough water seakeeping trials, (b) comparing these limits to the safe operational envelope established by the American Bureau of 
Shipping, and (c) quantify the adequacy of the structure against global loads, as well as, slam events [36].

As indicated in [36], a total of 16 sensors were placed for measuring the structural response due to global loading. These sensors, denoted as T1-1 to T1-16, recorded the global bending stresses, pitch connecting moments, and split responses. Another group of sensors, T2-1 to T2-9 and T2-12 to T2-21, was installed to measure the stress concentration at various locations. Positions of the structural response sensors (i.e., T1 and T2 sensors) were selected based on detailed finite element analysis and previous experience with similar vessels [36]. Data recorded by these sensors have a sample rate of $100 \mathrm{~Hz}$. Seakeeping trials were set up to expose the ship to different operational conditions covering multiple speeds, wave headings, and sea states. Thus, the trials were performed by executing octagon patterns where wave headings of $0^{\circ}$, $45^{\circ}, 90^{\circ}, 135^{\circ}, 180^{\circ}, 225^{\circ}, 270^{\circ}, 315^{\circ}$, and $360^{\circ}$ were encountered. However, considering the symmetry of the vessel, most of the runs were executed to cover only 5 heading angles. A total of 22 trial octagons have been performed at different speeds ranging between 2 and 35 knots at sea states 4 and 5. To study the effect of the ride control system on the structural response, a portion of those trial octagons was performed with the T-foil deployed while the rest was performed with the T-foil retracted. Slam load analysis performed by [17] showed that deploying the T-foil may slightly increase the slam pressure; however, it reduces the rate of slams. The study by Brady [17] was based on a comparison at speed 20 knots with no assessment with respect to fatigue, which is sensitive to both the pressures and the number of cycles. In this paper, a comparison of the fatigue response with respect to the T-foil deployment is performed at different operational conditions.

\section{Fatigue Analysis}


For fatigue analysis, the global response (i.e., T1) or stress concentration sensors (i.e., T2) can be used. Since many of the construction details have no direct match in the design guides, the nominal stress approach was not used in this study. Thus, the T2 strain gages are used with the hot spot structural stress S-N approach. Among those sensors, the sensor T2-4, placed to measure the bending response on the keel frame 26 on the port side, is analyzed herein. This sensor and its mirrored sensor T2-5, installed on the same frame but on the starboard side, show the highest strain response among all the T2 sensors. The location of frame 26 and the sensor T2-4 are shown in Fig. 3-(b) and 3-(c), respectively.

The strain gage measurements provide the loading effects for the fatigue assessment process. Since strains at the studied T2 sensor are well below the yield limit, Hooke's law is used to convert strains to stress values. For the resistance, the S-N relationship based on the hot spot approach proposed in [19] is used herein. This approach provides the mean S-N line based on regression analysis of 21 tests reported in [40]. In this paper, both deterministic and probabilistic fatigue assessments are performed. For the deterministic case, the design curve is obtained by shifting the mean S-N line by two standard deviations of $\log (A)$ to the left [2]. On the other hand, for reliability analysis, the mean S-N line is used. Both the design and the mean S-N line are plotted in Fig. 4. The intercepts of the adopted design and mean S-N lines are reported in Table 1.

\section{Analysis of SHM Data}

Ship structures are normally subjected to various simultaneous loading actions, as low frequency (i.e., wave induced), high frequency, still water and thermal loadings. The still water and thermal loadings have, usually, very low frequency and they affect only the mean stresses. Therefore, 
they have minimal effect on fatigue damage accumulation [7]. The response due to wave induced and dynamic loadings can be captured using strain measurements recorded by monitoring systems showing, typically, the overall response to both loading conditions. Since the effect of this combined load on the fatigue damage accumulation is herein analyzed, it has not been necessary to identify low and high frequency load components. This is in contrast with ultimate load capacity analyses in which the decomposition into low and high frequency loads is essential [13]. However, digital filters have been used herein to remove low amplitude stress cycles associated with very high frequencies induced by external noise and having negligible effect on the fatigue accumulation. After analyzing the Fourier transforms of signals recorded during various operational conditions, it has been chosen to process all signals with a low-pass Butterworth filter with $7.0 \mathrm{~Hz}$ cut-off frequency. A sensitivity analysis has been performed to investigate the effect of the cut-off frequency on the annual fatigue damage accumulation, showing only marginal increase in the annual fatigue damage accumulation for cut-off frequencies above 7 Hz. In Figs. 5-(a) and 5-(b), the amplitudes of the Fourier transform of two strain signals recorded at speeds 20 and 35 knots, respectively, are plotted. The raw signal, in the time domain, is shown in Fig. 6-(a) for run 133, and a close-up look is shown in Fig. 6-(b) to demonstrate the effect of the filtering process. The MATLAB signal processing toolbox in version 2012a [41] has been used.

After filtering the signal, the rainflow algorithm [42] is used to construct the stress range bin histograms and obtain the average number of cycles for each operational condition. The resulting stress range histograms are used to find the equivalent constant amplitude stress range using Eq. (4). A distribution fitting process is performed, using the maximum likelihood method, to find the best fit for the stress range data among multiple candidate distributions, namely, 
lognormal, Rayleigh, Weibull, and exponential. Goodness of fit is judged using the KolmogorovSmirnov test [43] as well as probability plots. Analyses of the fitting data showed that the Weibull distribution provides the best fit for the short term stress range records. The fitting results are illustrated in Fig. 7 for the Run 70 with speed 20 knots for head sea conditions; in particular, Fig. 7-(a), (b), and (c) show the probability plot of the stress range data for the Weibull, lognormal, and exponential distributions, respectively. Additionally, Fig. 7-(d) shows the stress range bin histogram along with the best distribution fit.

\section{Fatigue Damage Accumulation}

Fatigue damage assessment is performed for the detail equipped with the sensor T2-4 using the strain measurements for the range of available operational conditions. Eq. (2) is used for this task considering an annual ship operation rate $o_{r}=2 / 3$ (i.e., it is considered that the ship is operated $2 / 3$ of the time). The results of such analysis provide indications on the effect of different operational conditions on the fatigue damage. Fig. 8-(a) shows the annual damage accumulation with respect to the speed for sea states 4 and 5. It should be noted that the strain records of the operational condition at sea state 5 with speed 20 knots and heading angle $0^{\circ}$ were not included in the monitoring data. As expected, the damage accumulation increases with the speed. Higher sea states have significant effect on the damage accumulation especially at speeds higher than 30 knots. At 35 knots, an increase of $250 \%$ in the damage accumulation is found when the sea state changes from 4 to 5 . Additionally, the study is performed with respect to the significant wave height and the encountered wave period, which is dependent on the ship speed. Results reported in Fig. 8-(b) illustrate the variation of the annual fatigue damage accumulation of the detail with respect to the encountered wave period for different values of the significant wave height $H$. As shown, the damage accumulation decreases with the increase in the encountered wave period. 
Additionally, the accumulation increases with the increase in the significant wave height $H$; this effect is amplified for low values of the encountered wave period (i.e., at higher navigation speeds). It is also observed that the difference in the damage accumulation occurring at sea state 4 for speeds 20 and 30 knots is very small. This can be attributed to the difference in the wave period between the two operational conditions.

The effect of the T-foil deployment on the fatigue damage accumulation at various operational conditions has been also investigated. Results are depicted in Fig. 9 for sea state 5 and head sea condition, considering various speeds, and T-Foil deployed or retracted. At low speeds (15 knots and below) the effect of the T-foil on the damage accumulation seems negligible. However, with the increase in speed, a different behavior is observed; at 30 knots, the damage accumulation is lower with the $\mathrm{T}$-foil retracted, with a reduction of $30 \%$ in the damage accumulation when compared to the case with the T-foil deployed; whereas, at 35 knots, the Tfoil deployment reduces the damage accumulation by about $30 \%$. Therefore, with respect to the fatigue damage accumulation, the T-foil seems to be not effective at speeds 30,15 , and 2 knots.

The effect of the heading angle is next analyzed; the annual damage accumulation with respect to the heading angle at speed 15 knots is reported in Fig. 10 for different sea states. The same trend in the results is observed for the two considered sea states with respect to the heading angle; however, an upwards shift in the damage accumulation occurs with the higher sea state. The damage accumulation is maximum for head sea condition and minimum for beam (i.e., heading angle $=90^{\circ}$ ) and following seas (i.e., heading angle $=180^{\circ}$ ). For heading angles $45^{\circ}$ and $135^{\circ}$, the damage accumulation level is almost equal, residing at around $75 \%$ of that occurring at head sea conditions. Similar results were found for the case of T-foil deployed, shown in Fig. 11(a). The damage accumulation has similar values to the case of T-foil retracted at most heading 
angles, except for the head sea (i.e., heading angle $=0^{\circ}$ ) and the following sea in which the Tfoil deployment causes a slight increase in the damage accumulation. This observation is in line with the results shown in Fig. 9. The effect of the heading angle on the fatigue damage accumulation trend changes with higher speed. Fig. 11-(b) shows the annual damage accumulation at speed 35 knots, for different heading angles and T-foil deployed or retracted. As expected, the $\mathrm{T}$-foil reduces significantly the damage accumulation for most heading angles except $135^{\circ}$ and $180^{\circ}$. In these cases, the damage accumulation shows no sensitivity with respect to the T-foil condition. Figs. 12-(a) and (b) provide, in polar plot representation, the annual damage accumulation at speeds 15 and 30 knots for sea states 4 and 5, respectively. As shown, the speed of the ship has a significant effect on the damage accumulation at different heading angles and sea states.

\section{Fatigue Reliability}

Fatigue reliability for the individual operational conditions is found by means of Eqs. (9) and (10) using the software CalREL [32] that implements second order reliability method (SORM). Fig. 13 plots the time-variant reliability index for different operational conditions, assuming that the ship is subjected to the same operational condition throughout its service life, with an annual operational rate $o_{r}=2 / 3$. Fig. 13-(a) shows the reliability profiles at speed 30 knots for different sea states whereas Fig. 13-(b) highlights the effect of the speed on the fatigue reliability by showing the fatigue reliability profile for speeds 15,20 , 30, and 35 knots, at sea state 5. Fig. 13(c) shows a comparison between the reliability profiles obtained with the T-foil deployed and retracted at speed 35 knots. As expected from previous results, using the T-foil improves the reliability at high speeds, increasing the predicted fatigue life by more than $100 \%$, specifically, 28.1 years and 13.4 years for target reliability indices of 2.0 and 3.0, respectively. The effect of 
the heading angle is shown in Fig. 13-(d) in which the reliability is plotted for $0^{\circ}, 45^{\circ}$ and $90^{\circ}$ heading angles. For other heading angles, since the damage accumulation is significantly low, the resulting reliability profiles are extremely high compared to those associated with the considered angles; thus, these profiles have been excluded from the plot.

When the real operational profile recorded in the ship log files is considered, a different reliability profile has to be expected. If the time spent in each operational condition or the probability of being in each operational condition is known, the overall fatigue reliability, as a result of being exposed to multiple operational states, can be found using Eq. (19). Additional information on obtaining these probabilities and the overall operational profile of a ship can be found in [44]. This information, in conjunction with the SHM data recorded during the sea keeping trials at an early stage of the ship service life, can be used to project the long-term reliability profile of the ship. As an example, a simple operational profile is provided in Table 2 where the probabilities of being in each sea state, heading angle, and speed are given for three different operational conditions (i.e., C1, C2 and C3). In this case, the reliability analysis is performed using the software CalREL. Fig. 14-(a) shows the reliability profiles of each operational condition, assuming complete operability of the ship in this condition, and the overall reliability profile arising from the real operability in the mixed operational states. The target service life can be easily estimated by establishing a reliability index threshold $\beta_{\text {target }}$. Setting $\beta_{\text {target }}=2.0$ returns a fatigue life of 13.30 years at the detail, whereas, $\beta_{\text {target }}=3.0$ gives 6.38 years of fatigue life. This fatigue life seems to be relatively short, especially when compared to other types of structures such as steel ships and bridges. However, as previously mentioned, the analyzed detail shows significantly higher strain response compared to other monitored 
locations. This suggests the need for more frequent inspections at the analyzed detail to detect and repair any cracks before they reach their critical sizes.

The simplified approach provided by Eqs. (20)-(22) is also used to find the fatigue life at each operational state and the overall fatigue life at the detail. The time to failure for each operational state and given by Eq. (21), is listed in Table 2 for target reliability indices 2.0 and 3.0. Using Eq. (22) for the listed operational states returns a fatigue life of 13.27 years and 6.34 years for target reliability index of 2.0 and 3.0, respectively. Results obtained by Eqs. (20)-(22) are within $5 \%$ of those calculated using SORM. However, this simplified method can be used to immediately update the fatigue life, if any future changes should affect the ship operational profile. For example, the updated operational profile given in Table 3 is analyzed. This profile provides the same operational states reported in Table 2 with modified probabilities; in addition, more operational states characterized by having the T-foil retracted for speeds lower than 35 knots are considered. The fatigue life can be easily updated to account for the modified operational profile. Using Eqs. (20)-(22), a fatigue life of 15.83 and 7.56 years is obtained for $\beta_{\text {target }}=2.0$ and 3.0, respectively, compared to 15.92 and 7.65, given by the SORM. As shown, both methods yield similar fatigue life estimates for different target reliability indices.

\section{CONCLUSIONS}

In this paper, fatigue assessment of aluminum high speed naval vessels with respect to individual operational conditions has been performed. In addition, an approach for the reliability-based fatigue assessment and life estimation has been proposed. Operational data of the ship, in terms of the time spent at each operational condition (i.e., sea state, heading angle, and speed), were used, in conjunction with the sea trial SHM data, to predict the long-term fatigue reliability of a ship detail. The hot spot structural stress approach was used for the fatigue assessment; however, 
the proposed methodology can be applied to any stress analysis method. The proposed approach allows to (a) evaluate the reliability-based fatigue life in a straightforward manner; (b) analyze the effect of different operational conditions on the fatigue damage accumulation to adjust the ship safe operational profile and minimize the probability of fatigue failures; (c) plan the ship route in order to minimize the fatigue damage accumulation; and (d) promote the real-world application of reliability-based methods using SHM information. The proposed fatigue life estimation method is applied to strain data of the HSV-2 obtained during the seakeeping trials of the vessel. The following conclusions can be drawn:

- Some combinations of speeds, sea states, and wave headings have a significant effect on fatigue damage accumulation. These operational conditions should be identified and they should be avoided to prevent the accelerated damage to the ship structure.

- The effect of the T-foil on the damage accumulation has to be investigated carefully for different operational conditions. For the analyzed vessel, it was found that at speeds lower than 30 knots, the damage accumulation is larger when the T-foil is deployed. However, for speed 35 knots, the T-foil deployment significantly reduces the damage accumulation.

- Although fatigue is a major limit state affecting the ship safety, other limit states, such as the serviceability and ultimate strength should also be studied using SHM information including Bayesian updating [45], [46].

- The proposed approach enables the active integration of fatigue limit state in the lifecycle management framework in which inspection and maintenance optimization based on reliability [47] and life-cycle cost analysis [48] can be performed, as well as the active 
route planning to minimize the fatigue damage accumulation at critical details during voyages.

\section{ACKNOWLEDGMENTS}

The authors appreciate the guidance and overall support from Dr. Paul E. Hess III, Structural Reliability Program Director, ONR, Code 331.

\section{DECLARATION OF CONFLICTIN INTERESTS}

The opinions presented in this article are those of the authors and do not necessarily reflect the views of the sponsoring organizations.

\section{FUNDING}

This study was supported by the U.S. Office of Naval Research (ONR) Awards N00014-08-10188 and N00014-12-1-0023.

\section{REFERENCES}

[1] Sielski, R.A., 2007. Research needs in aluminum structure. Proceedings of the 10th International Symposium on Practical Design of Ships and Other Floating Structures, American Bureau of Shipping, Houston, TX.

[2] Fisher, J.W., Kulak, G.L. and Smith, I.F., 1998. A fatigue primer for structural engineers. 16-33. National Steel Bridge Alliance, American Institute of Steel Construction, Chicago, IL

[3] Paik, J. K. and Frieze, P. A., 2001. Ship structural safety and reliability. Progress in Structural Engineering and Materials, 3: 198-210.

[4] Ayyub, B. M., Assakkaf, I. A., Kihl, D. P. and Siev, M. W., 2002. Reliability-based design guidelines for fatigue of ship structures. Naval engineers journal, 114(2): 113138.

[5] ABS., 2010. Spectral-based fatigue analysis for floating production, storage and offloading (FSPO) installations. American Bureau of Shipping, Houston, TX. 
[6] DNV - Det Norske Veritas., 2010. Fatigue methodology of offshore ships, Det Norske Veritas Classification A.S., CN 30.9, Høvik, Norway.

[7] Munse, W.H., et al., 1982. Fatigue Characterizations of Fabricated Ship Details for Design. Ship Structure Committee Report No. SSC-318, Ship Structure Committee, Washington, DC.

[8] Glen, I.F., Dinovitzer, A., Paterson, R.B., Luznik, L., and Bayley, C., 1999. Fatigueresistant detail design guide for ship structures. Ship Structure Committee Report No SSC-405, Ship Structure committee, Washington, DC

[9] Eurocode 9, 2009. Design of Aluminium Structures Part 1-3, Additional rules for structures susceptible to fatigue. CEN - European committee for Standardisation, Brussels, Belgium.

[10] DNV - Det Norske Veritas., 1997. Fatigue analysis of high speed and light craft, Det Norske Veritas Classification A.S., CN 30.9, Høvik, Norway.

[11] Collette, M., 2005. Strength and reliability of aluminum stiffened panels. 139-198, A Thesis submitted for the Degree of Doctor of Philosophy, School of Marine Science and Technology, Faculty of Science, Agriculture and Engineering, University of Newcastle, UK.

[12] Hess, P.E., 2007. Structural health monitoring for high-speed naval ships. Proceedings of the 7th International Workshop on Structural Health Monitoring, Stanford, CA.

[13] Okasha, N.M., Frangopol, D.M., Saydam, D., and Salvino, L.W., 2011. Reliability analysis and damage detection in high-speed naval crafts based on structural health monitoring data. Structural Health Monitoring, 10(4): 361-379.

[14] Violette, F.L.M., et al. 1998. Basic Parameters Governing the Fatigue of Aluminum Ships. In 3rd International Forum on Aluminium Ships. Haugesund, Norway.

[15] Frangopol, D.M., 2011. Life-cycle performance, management, and optimisation of structural systems under uncertainty: accomplishments and challenges. Structure and Infrastructure Engineering, 7(6): 389-413.

[16] Kwon, K., and Frangopol, D.M., 2012. Fatigue life assessment and lifetime management of aluminum ships using life-cycle optimization. Journal of ship research, 56(2): 91-105.

[17] Brady T.F., 2004. Wave impact loading response measurement and analysis for HSV-2 from JLOTS and blue game rough water trials. NSWCCD-65-TR- 2004/32, Naval Surface Warfare Center, Carderock Division, West Bethesda, MD.

[18] Kwon, K., Frangopol, D.M., and Kim, S., 2013. Fatigue performance assessment and service life prediction of high-speed ship structures based on probabilistic lifetime sea loads. Structure and Infrastructure Engineering, 9(2): 102-115. 
[19] Collette, M. and Incecik, A., 2006. An approach for reliability-based fatigue design of welded joints in aluminum high-speed vessels. Journal of Ship Research, 50(3): 85-98.

[20] Salvino, L.W. and Brady, T.F., 2008. Hull monitoring system development using hierarchical framework for data and information management. Proceedings of the 7th International Conference on Computer and IT Applications in the Marine Industries (COMPIT'08), Liège, Belgium.

[21] Barsom, J.M. and Rolfe, S.T., 1999. Fracture and Fatigue Control in Structures: Applications of Fracture Mechanics. 3rd Edition, ASTM, West Conshohocken, PA.

[22] Kim, S., and Frangopol, D.M., 2011. Optimum inspection planning for minimizing fatigue damage detection delay of ship hull structures. International Journal of Fatigue, 33: $448-459$.

[23] Eurocode 3, 2010. Design of Steel Structures Part 1-9, Fatigue strength. CEN European committee for Standardisation, Brussels, Belgium.

[24] Ye., N, and Moan, T., 2008. Improving fatigue life for aluminium cruciform joints by weld toe grinding. Fatigue and Fracture of Engineering materials and structures, 31(2): $152-163$.

[25] Maddox, S.J., 2003. Review of fatigue assessment procedures for welded aluminum structures. International Journal of Fatigue, 25: 1359-1378.

[26] Radaj, D., Sonsino, C.M., and Fricke, W., 2006. Fatigue assessment of welded joints by local approaches. 2nd Edition, 33-90, Woodhead Publishing and Maney Publishing on behalf of The Institute of Materials, Minerals \& Mining, CRC Press, Boca Raton Boston, New York, Washington DC.

[27] Niemi, E., 1995. Stress Determination for Fatigue Analysis of Welded Components, 5365, International Institute of Welding, Abington Publishing, Abington, Cambridge.

[28] Miner M. A., 1945. Cumulative damage in fatigue. Journal of Applied Mechanics, 12(3): 159- 164.

[29] Fatemi, A., and Yang, L. 1998. Cumulative fatigue damage and life prediction theories: a survey of the state of the art for homogenous materials. International Journal of Fatigue, 20(1): 9-34.

[30] Kwon, K., and Frangopol, D.M., 2010. Bridge fatigue reliability assessment using probability density functions of equivalent stress range based on field monitoring data. International Journal of Fatigue, 32: 1221-1232.

[31] Estes, A.C. and Frangopol, D. M., 1998. RELSYS: A computer program for structural system reliability analysis. Structural Engineering and Mechanics, Techno-Press 6(8): 901-919. 
[32] Liu P.L., Lin H.Z., and Der Kiureghian A., 1989. CalREL User Manual, Department of Civil Engineering. University of California, Berkeley, CA.

[33] Hughes, O.F., 1988. Ship Structural Design. The Society of Naval Architects and Marine Engineers, Jersey City, NJ.

[34] Jensen, J.J., 2001. Load and Global Response of Ships. Elsevier Ocean Engineering Series, ed. R. Bhattacharyya and M.E. McCormick. Vol. 4, Elsevier, Oxford.

[35] Frangopol, D.M., Strauss, A., Kim, S., 2008. Bridge reliability assessment based on monitoring. Journal of Bridge Engineering, 13(3): 258-270.

[36] Brady T.F., 2004. HSV-2 Swift instrumentation and technical trials plan. NSWCCD-65TR- 2004/18, Naval Surface Warfare Center, Carderock Division, West Bethesda, MD.

[37] Incat., 2012. 98 Metre wave piercing catamaran. 3 Dec. 2012, < http://www.incat.com.au/domino/incat/incatweb.nsf/0/76457AADD2C1A987CA2571AF 0019EC66?OpenDocument $>$

[38] Brady T.F., 2004. Global structural response measurement of SWIFT (HSV-2) from JLOTS and blue game rough water trials. NSWCCD-65-TR- 2004/33, Naval Surface Warfare Center, Carderock Division, West Bethesda, MD.

[39] T.S.K., 2013. Microwave type wave height meter WM-2. The Tsurumi-Seiki Co. Ltd. 9 April $2013<$ http://www.tsk-jp.com/upload/product/pdf/WM2_E.pdf $>$

[40] Tveiten, B.W., 1999. Fatigue Assessment of Welded Aluminium Ship Details, A Thesis submitted for the Degree of Doctor of Philosophy, Department of Marine Structures, Norwegian University of Science and Technology.

[41] MathWorks., 2012. Signal processing toolbox ${ }^{T M}$ 6-user's guide. MathWorks Inc, Natick, MA.

[42] Downing, S. D. and Socie, D. F., 1982. Simple rainflow counting algorithms. International Journal of Fatigue, 4(1): 31-40.

[43] Ang., A. H-S. and Tang, W.H., 2007. Probability concepts in engineering. Emphasis on applications to civil and environmental engineering. 2nd edn. 278-302, Wiley \& Sons, New York.

[44] Glen, I.F., Paterson, R.B., and Luznik, L., 1999. Sea operational profiles for structural reliability assessment. Ship Structure Committee Report No SSC-406, Ship Structure committee, Washington, DC

[45] Strauss, A., Frangopol, D.M., 2008, Use of monitoring extreme data for the performance prediction of structures: Bayesian updating, Engineering Structures, 30(12): 3654-3666. 
[46] Zhu, B., Frangopol, D.M., 2013, Incorporation of SHM data on load effects in the reliability and redundancy assessment of ships using Bayesian updating, Structural Health Monitoring, 12(4): 377-392

[47] Frangopol, D.M., Estes A.C., 1997, Lifetime bridge maintenance strategies based on system reliability, Structural Engineering Inter. 7(3): 193-198.

[48] Frangopol, D.M., 1999, Life-cycle cost analysis for bridges, Chapter 9 in Bridge Safety and Reliability, ASCE, 210-236. 


\section{List of Figures}

Figure 1. Comparison between Eurocode S-N lines for steel [23] and aluminum [9] details; (a) rolled or extruded sections, and (b) members with longitudinal fillet weld

Figure 2. Schematic showing different stress types for fatigue analysis

Figure 3. The vessel under investigation (based on [17,35-37]); (a) general overview of the ship, (b) sketch of the plan view showing the location of the detail on Frame 26, and (c) the analyzed detail

Figure 4. The adopted hot spot structural stress S-N lines

Figure 5. Amplitudes of the Fourier transform of strain signals; (a) for speed 20 knots at head sea condition and sea state 5 , and (b) for speed 35 knots at head sea condition and sea state 4

Figure 6. A sample of SHM data; (a) raw signal without filtering, and (b) comparison of the response before and after the filtering process

Figure 7. Distribution fitting process; probability plot of the stress range for multiple distribution types (a) Weibull, (b) lognormal, and (c) exponential; (d) histogram and Weibull PDF of the stress range after filtering the signal

Figure 8. Variation of the annual fatigue damage accumulation of the detail with respect to (a) speed of the ship for different sea states, and (b) encountered wave period for different values of the significant wave height $H$

Figure 9. Variation of the annual fatigue damage accumulation of the detail with respect to the speed of the ship showing the effect of the T-foil deployment on the fatigue damage accumulation

Figure 10. Variation of the annual fatigue damage accumulation of the detail with respect to the heading angle for different sea states

Figure 11. Variation of the annual fatigue damage accumulation of the detail with respect to the heading angle showing the effect of T-foil deployment at (a) sea state 5 and speed 15 knots, and (b) sea state 4 and speed 35 knots

Figure 12. Comparison between the annual fatigue damage accumulation at speed 15 and 35 knots with respect to the heading angle for (a) sea state 4 with the T-foil retracted, and (b) sea state 5 with the T-foil deployed

Figure 13. Time-variant fatigue reliability index and its sensitivity with respect to the effect of (a) sea states, (b) speeds, (c) T-foil deployment, and (d) heading angle 
Figure 14. Time-variant fatigue reliability index for (a) original individual operational states and the overall reliability index profile, and (b) updated individual operational states and the overall reliability profile 
(a)

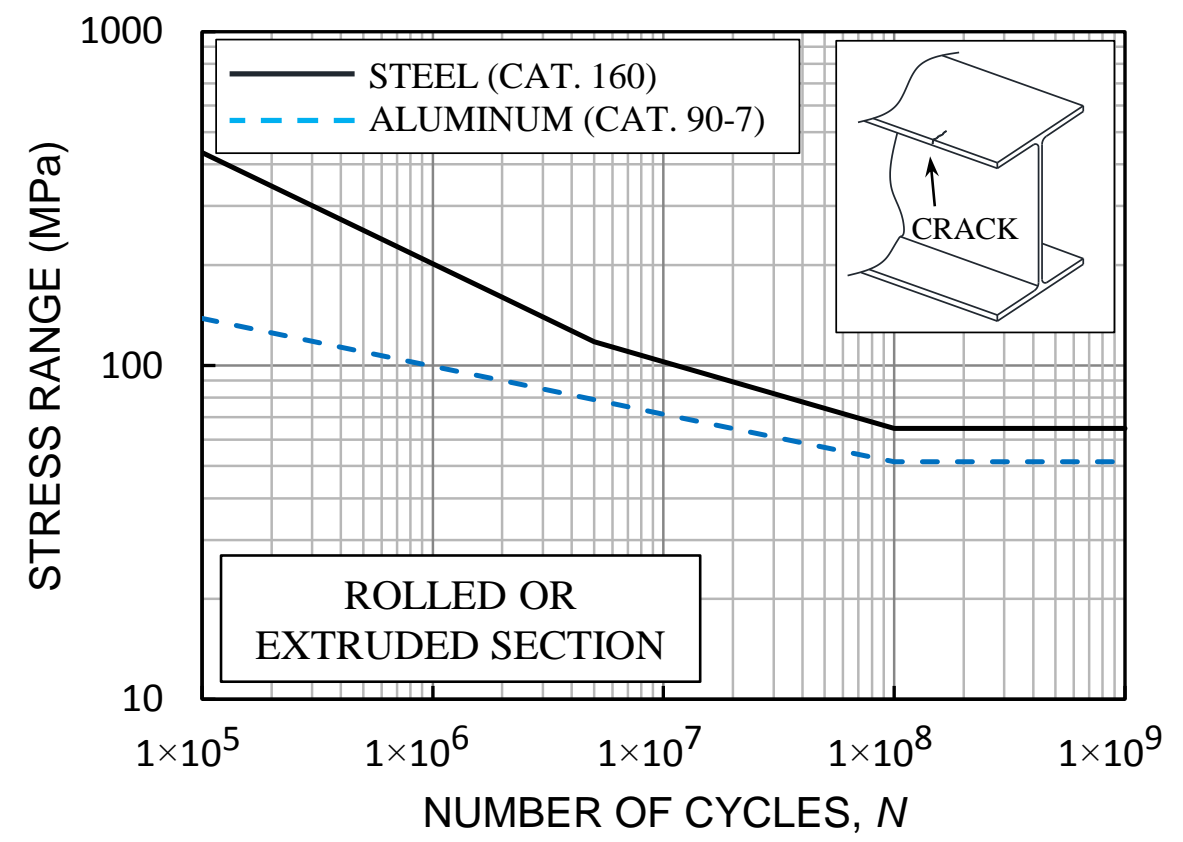

(b)

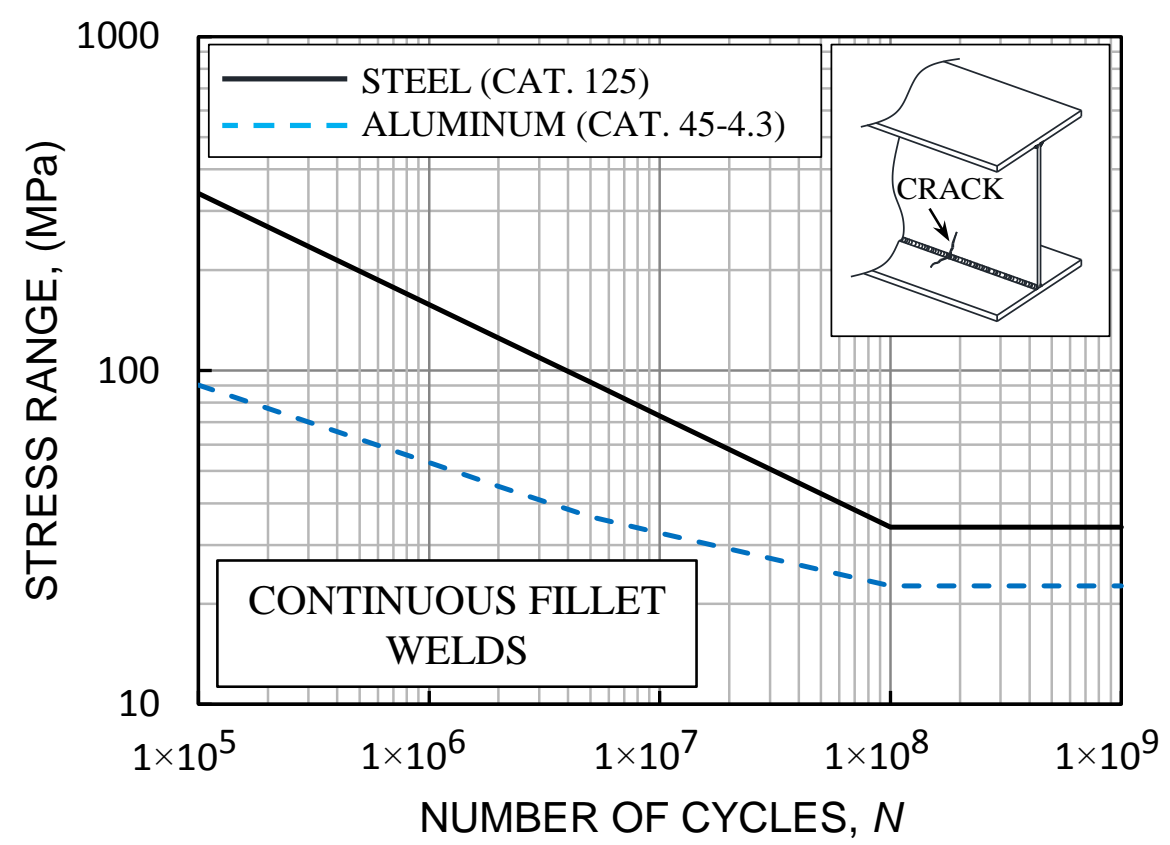

Figure 1 


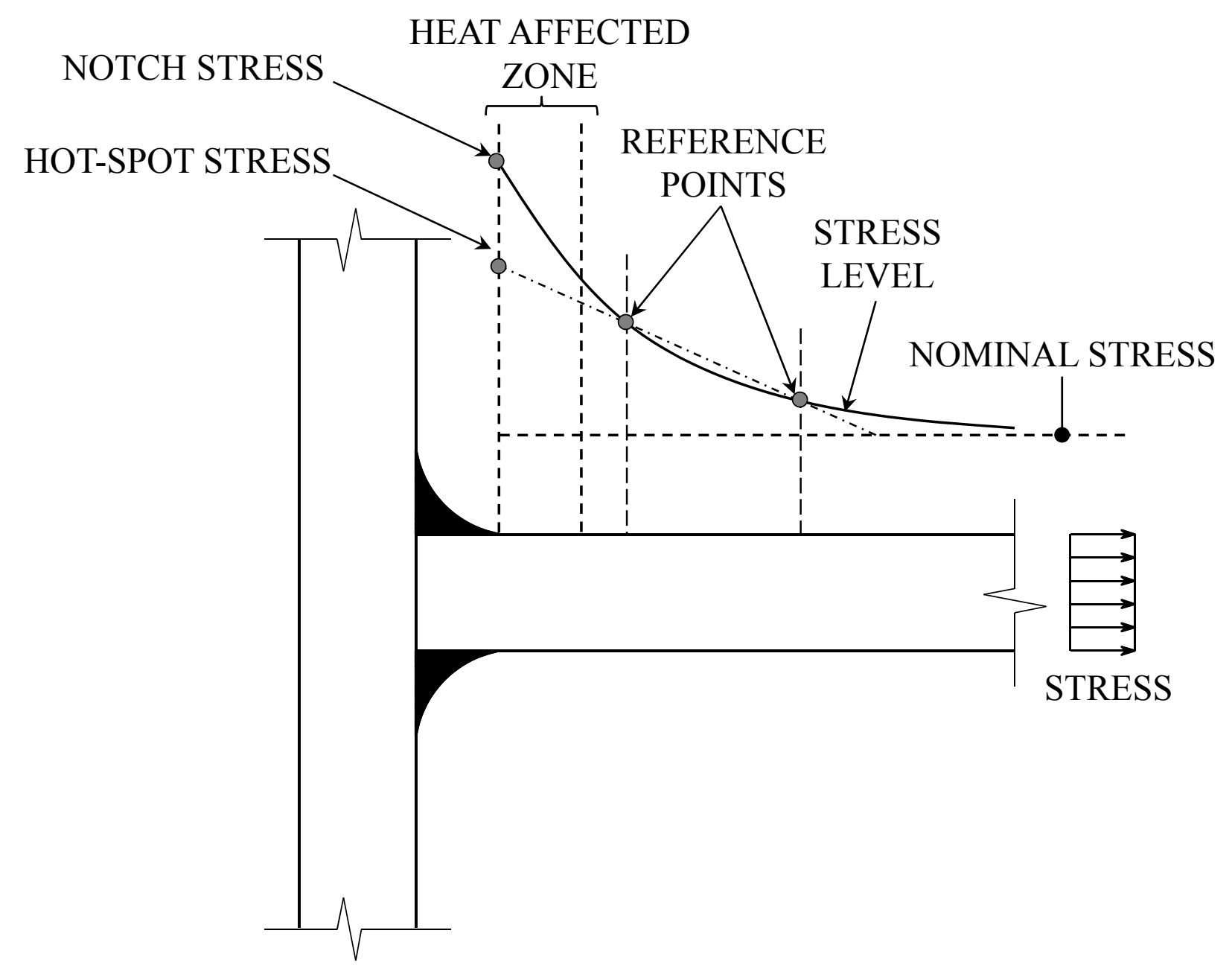

Figure 2 
(a)

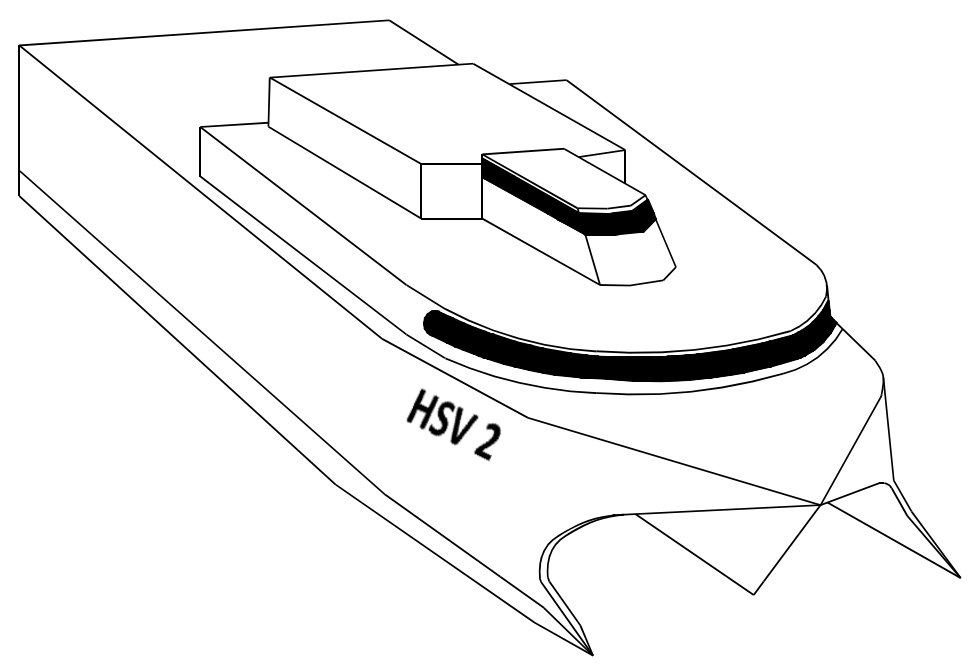

(b)
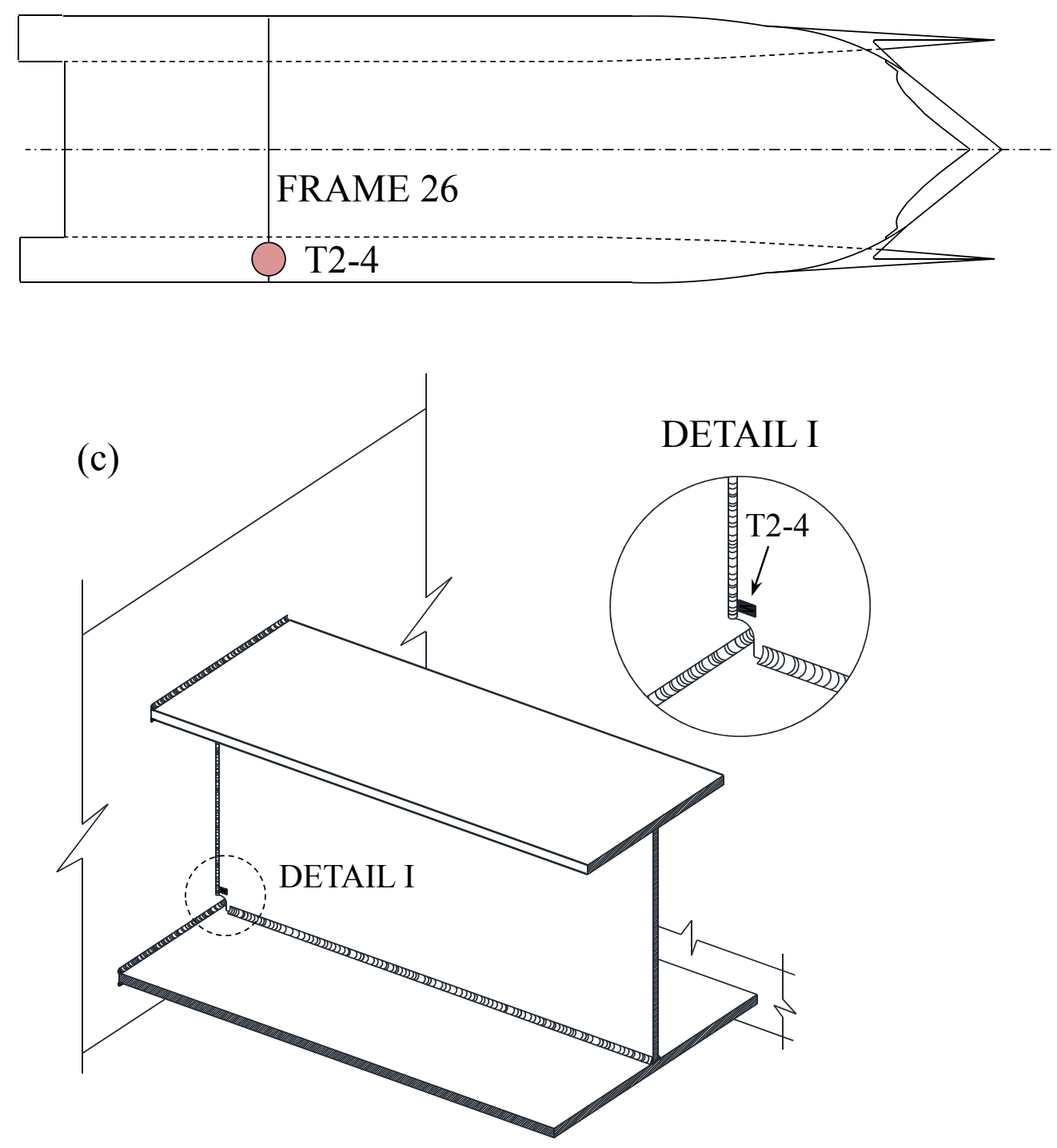

Figure 3 


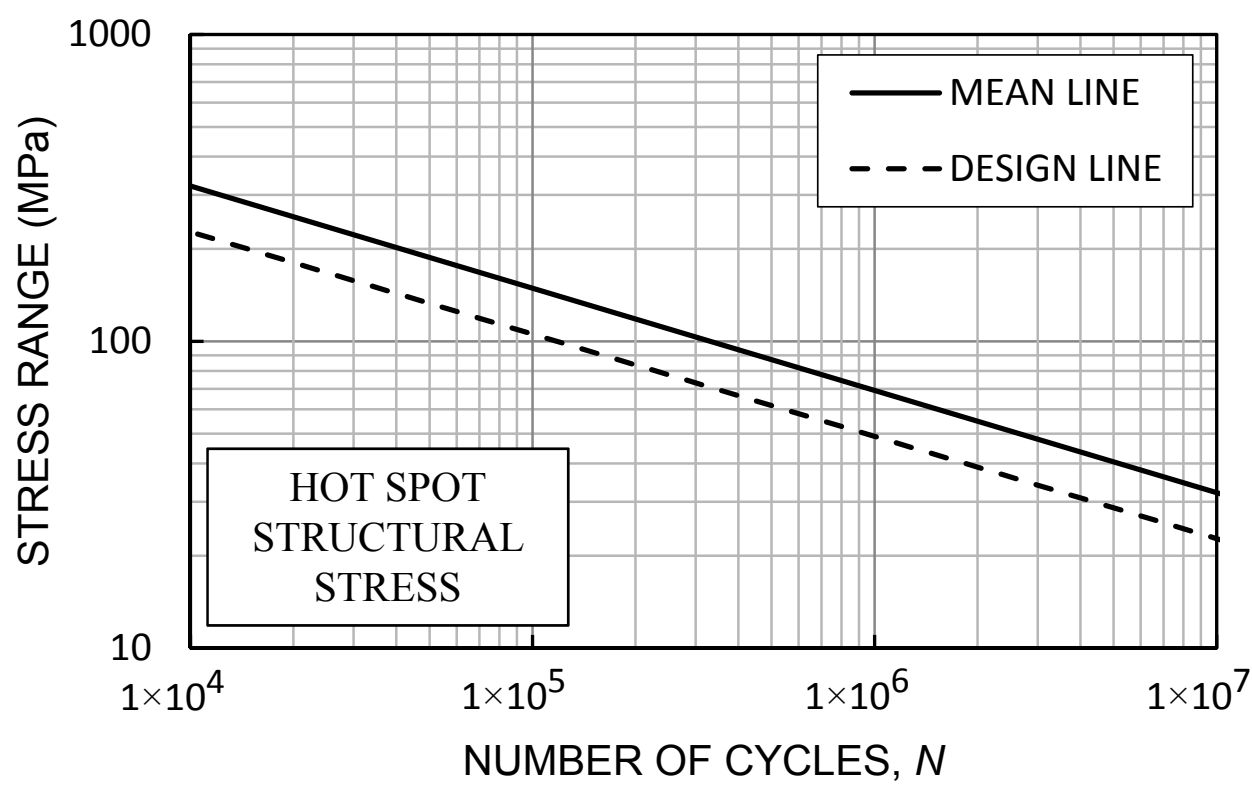

Figure 4 
(a)

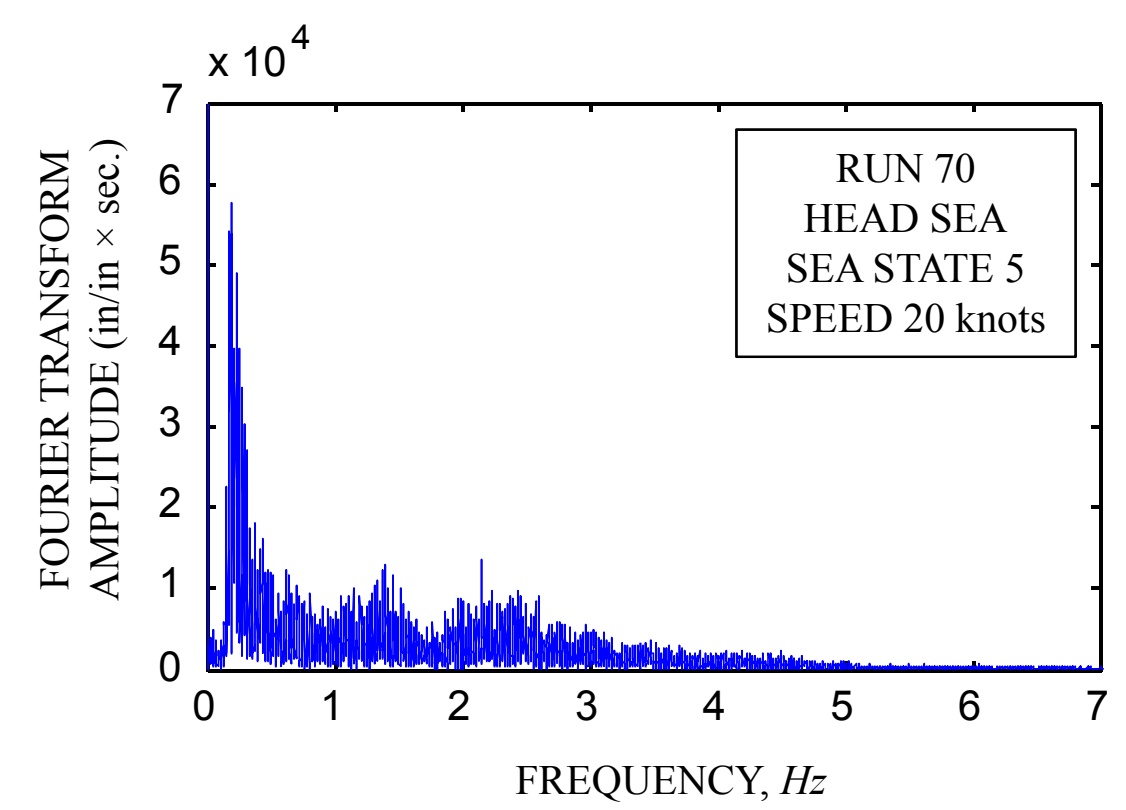

(b)

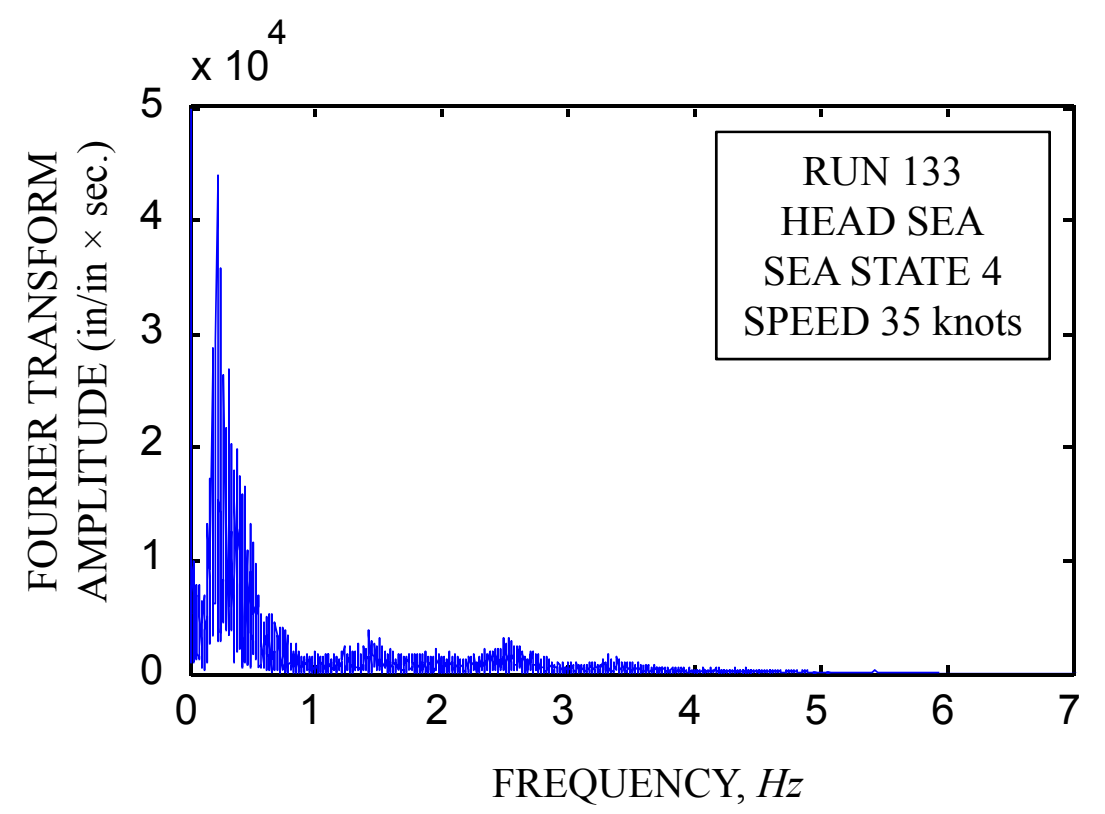

Figure 5 
(a)

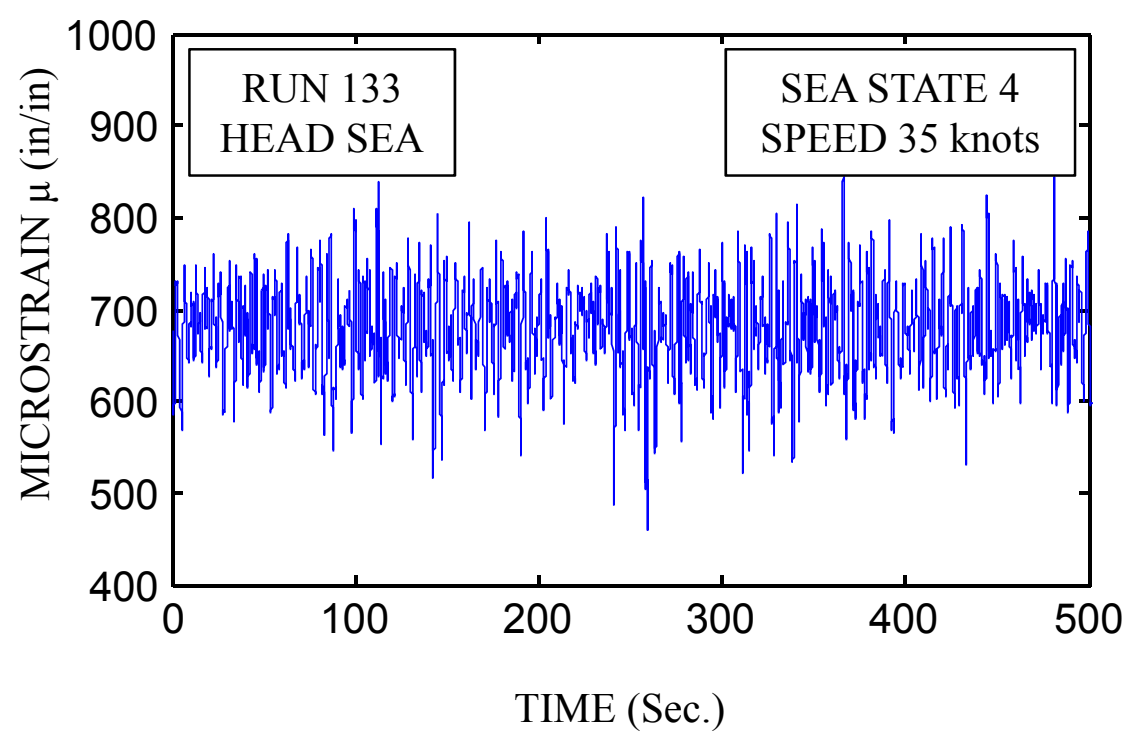

(b)

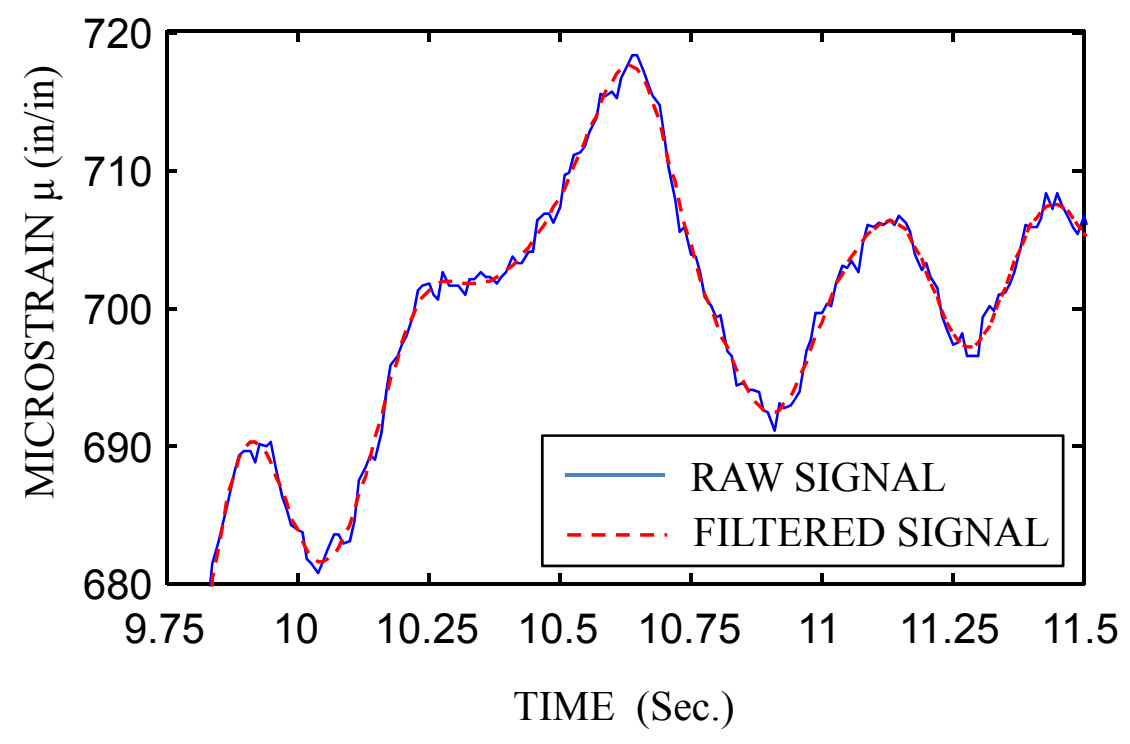

Figure 6 
(a)

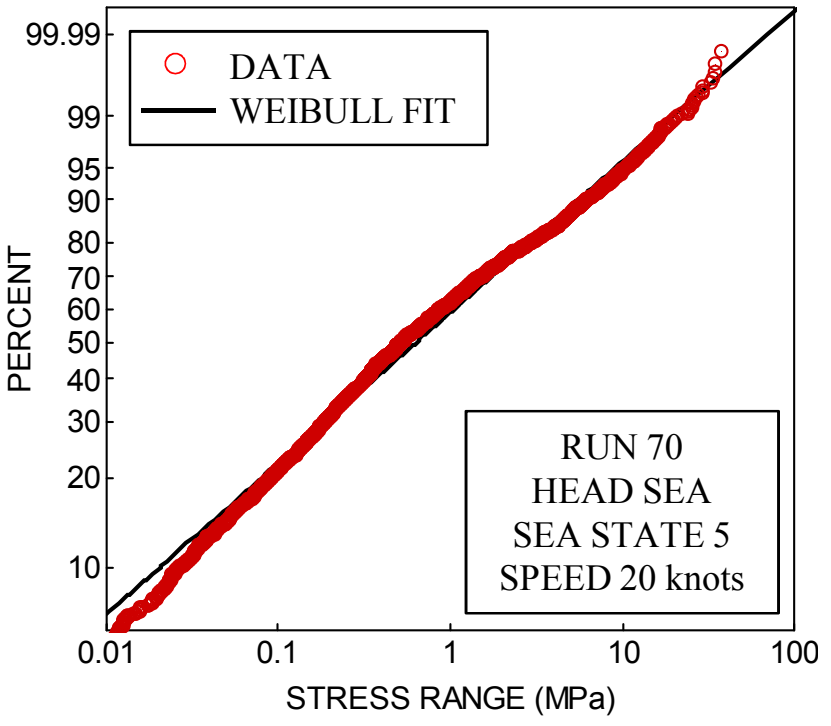

(b)

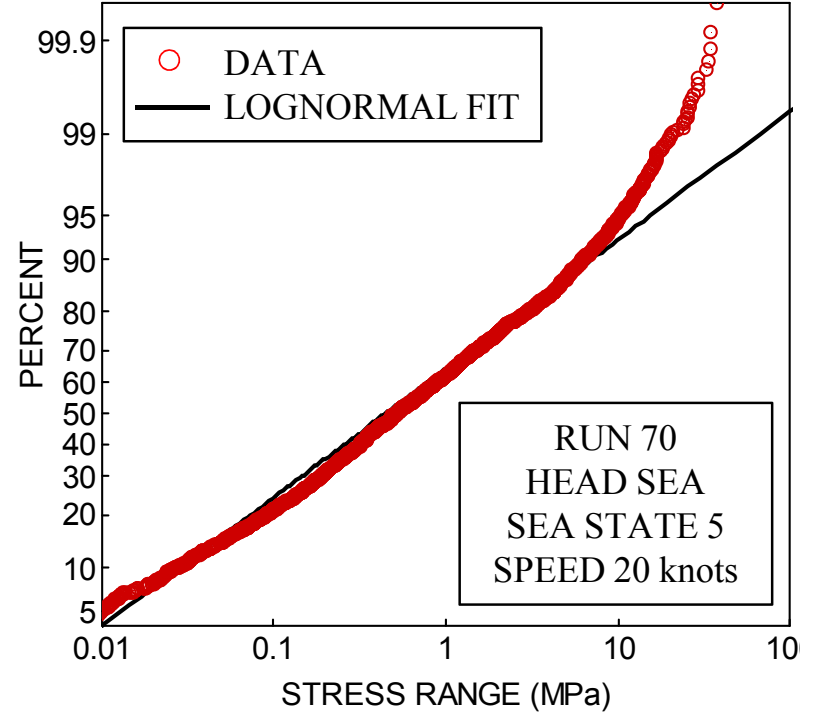

(c)

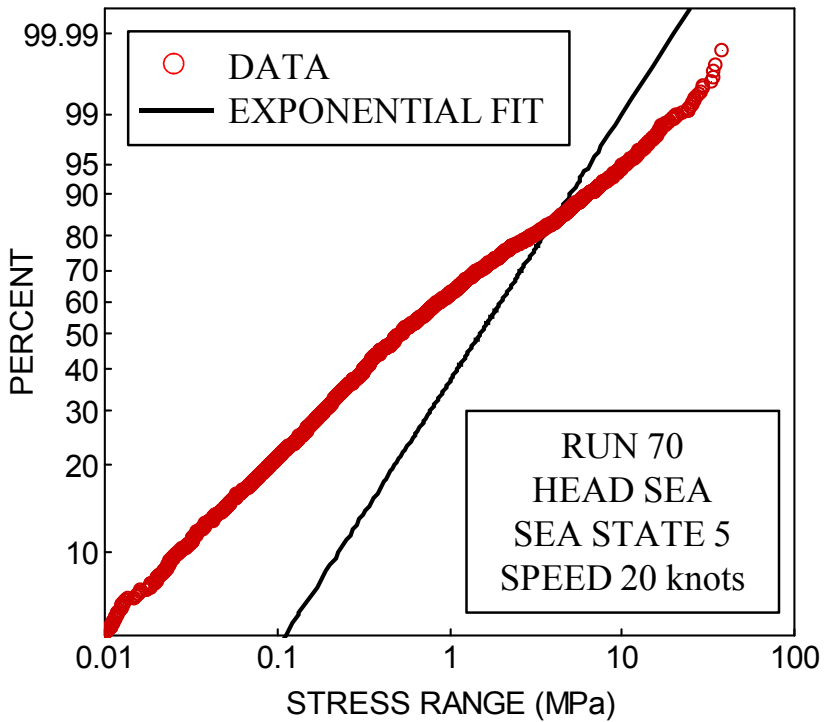

(d)

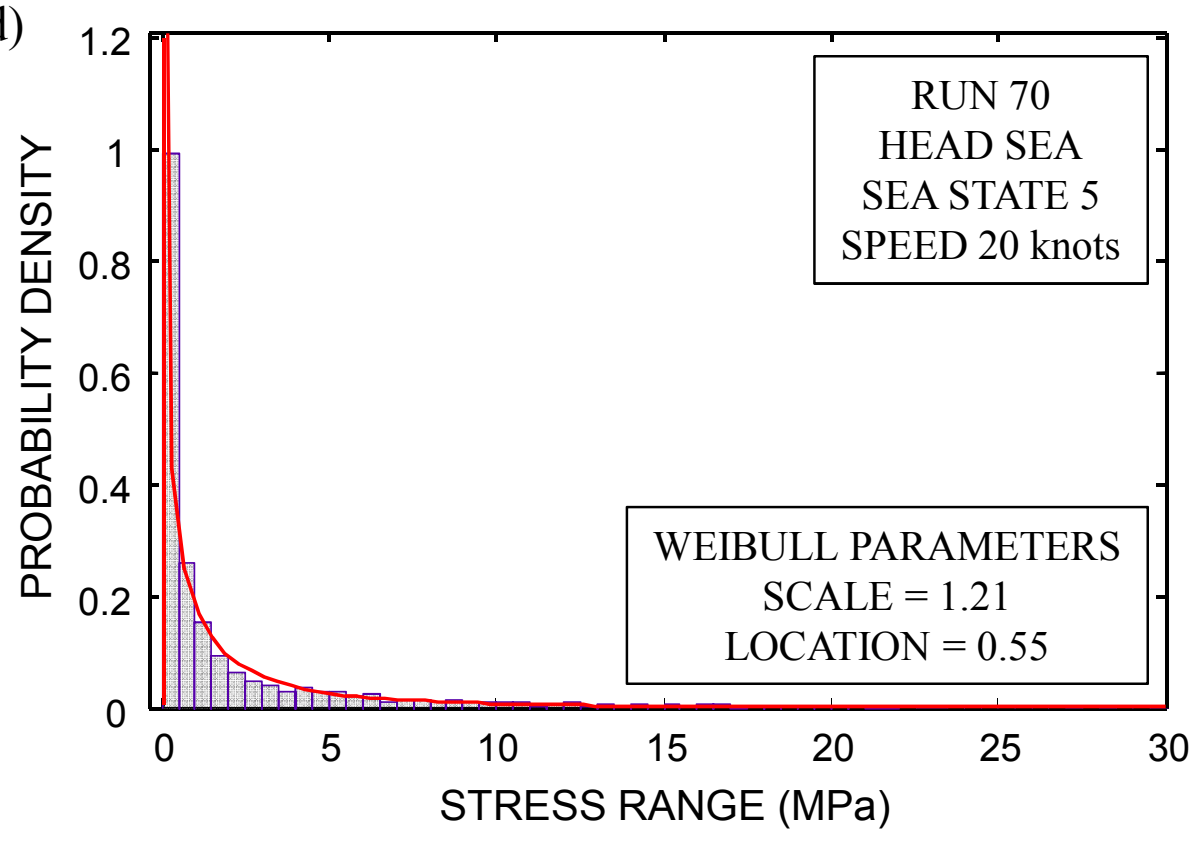

Figure 7 
(a)

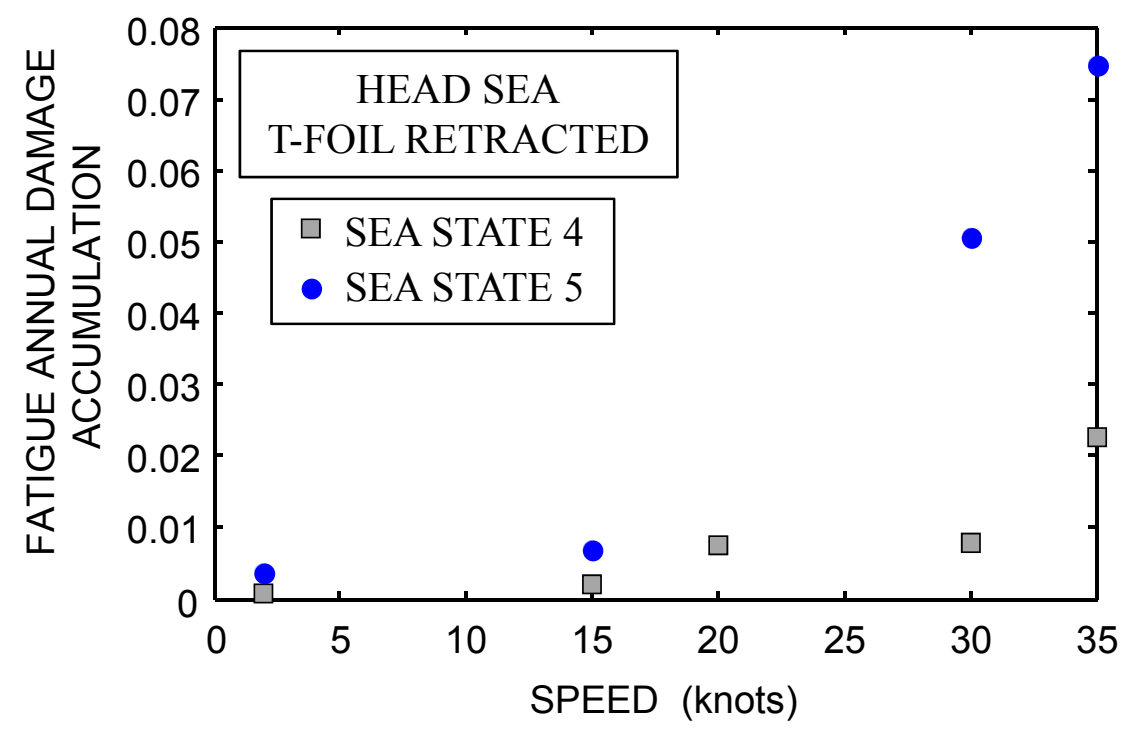

(b)

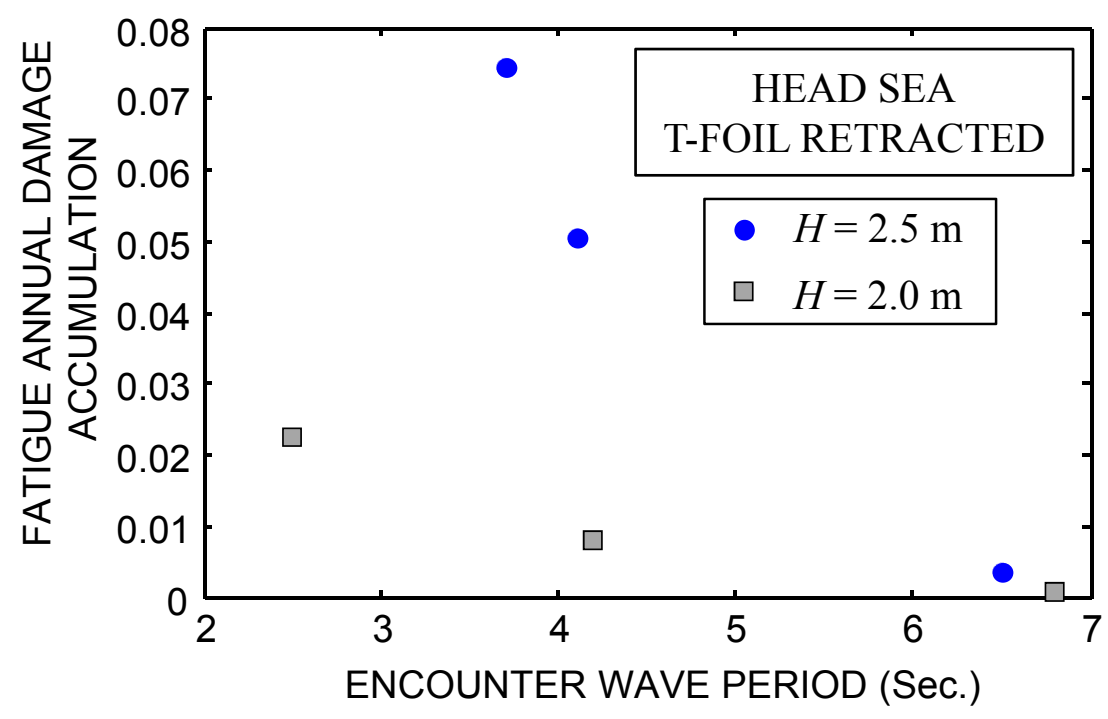

Figure 8 


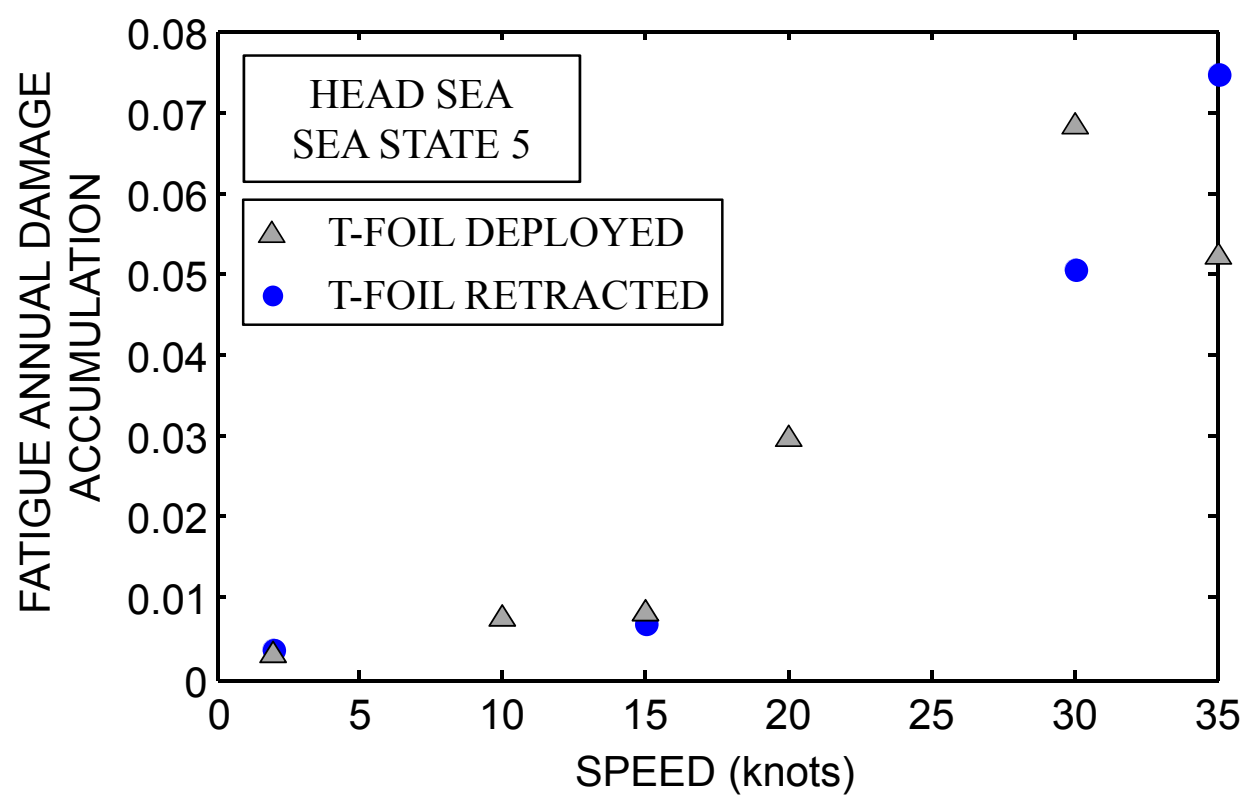

Figure 9 


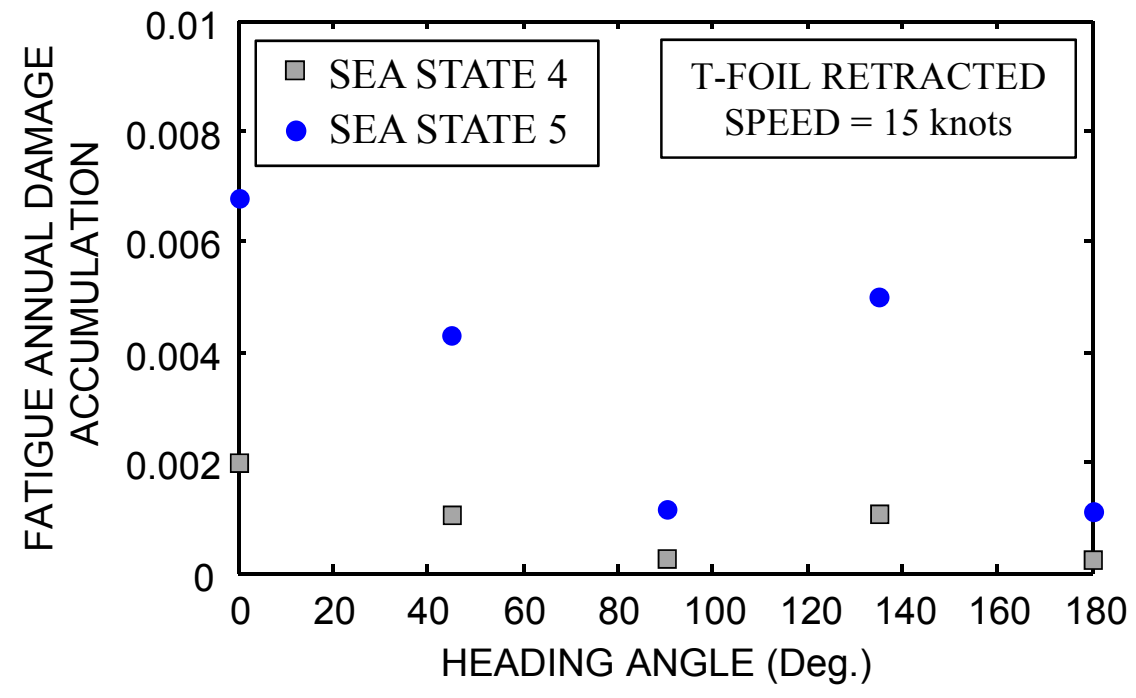

Figure 10 
(a)

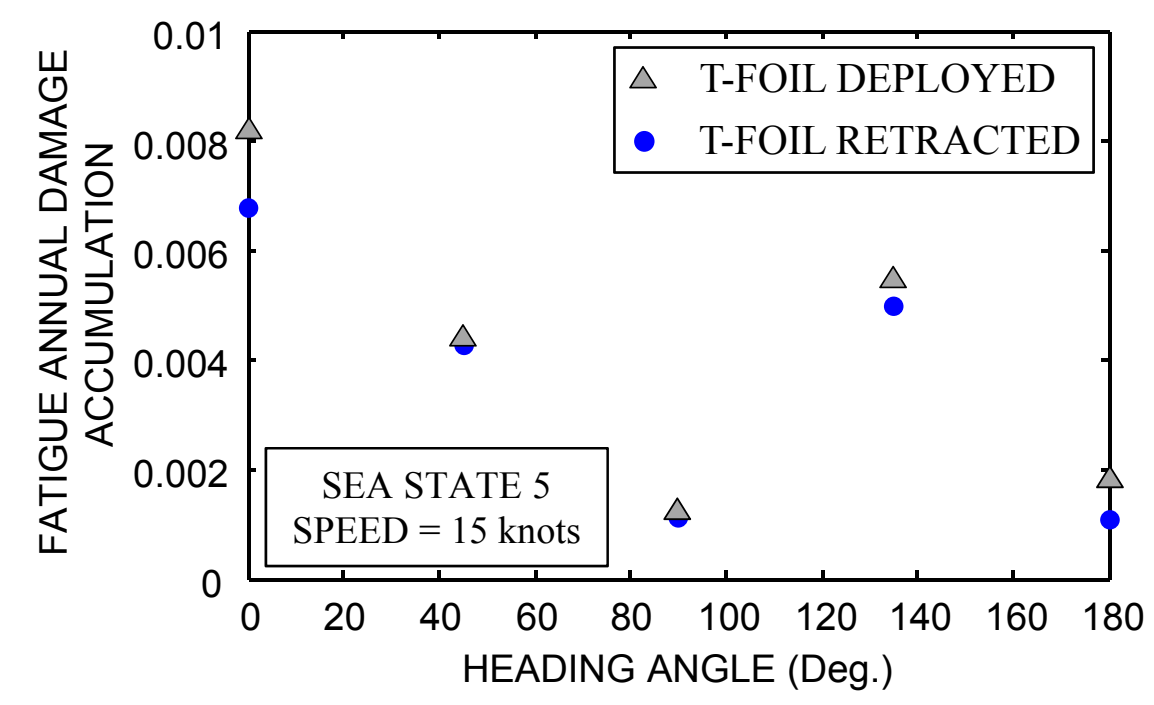

(b)

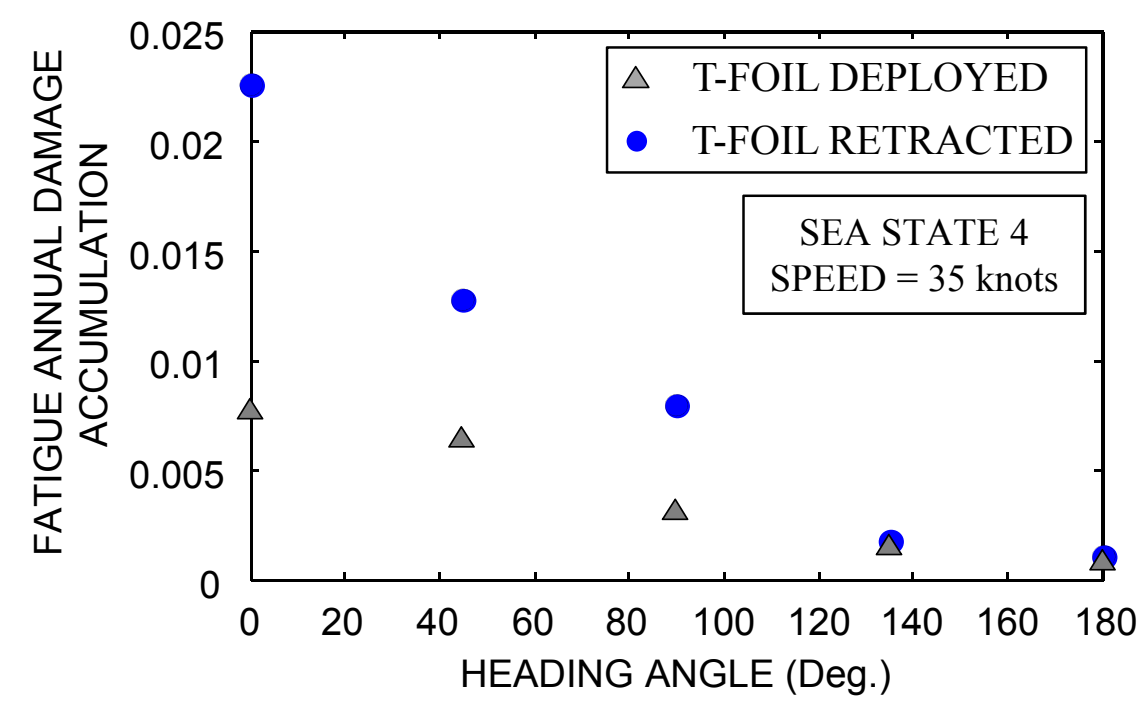

Figure 11 
(a)

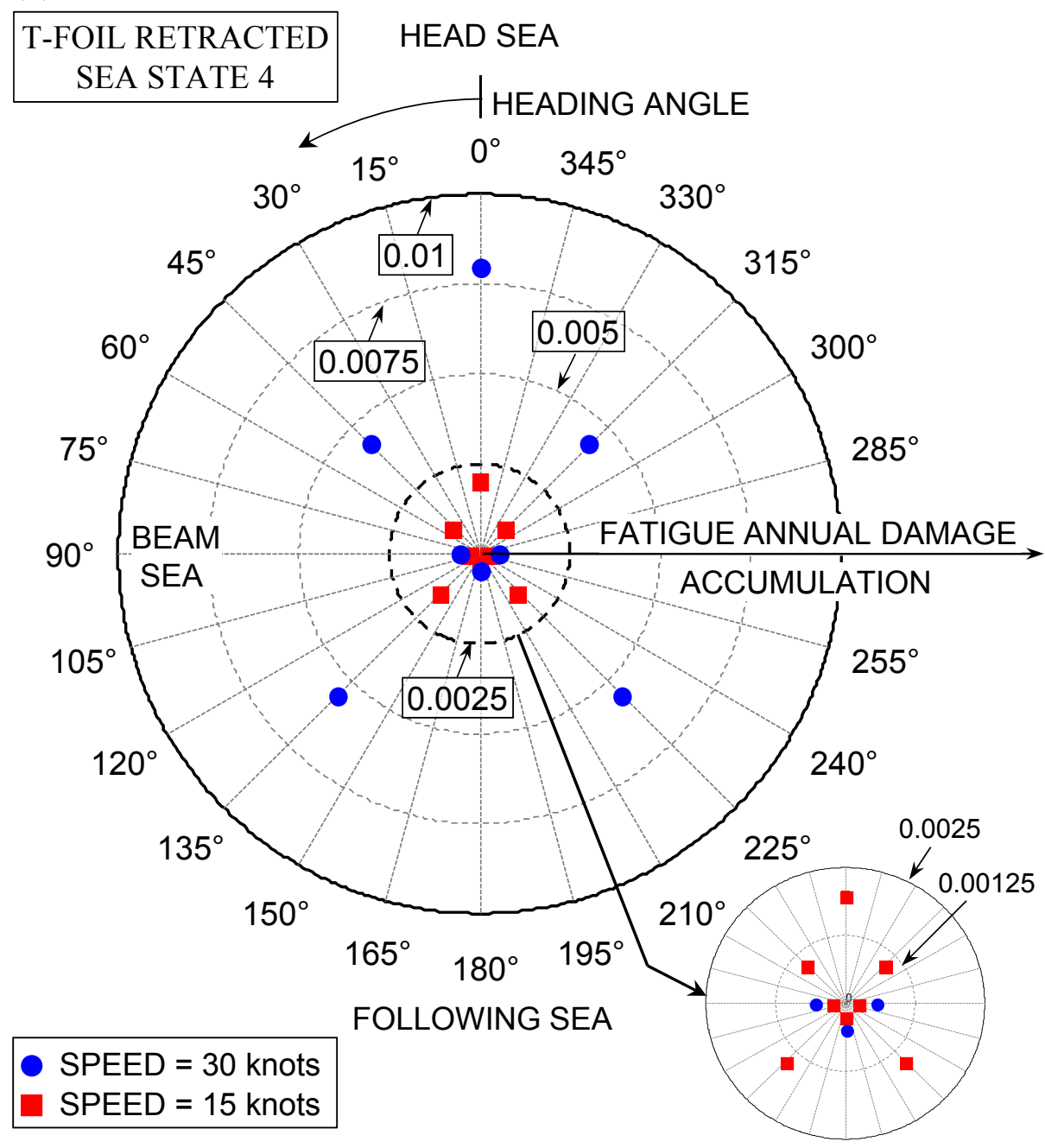

(b)

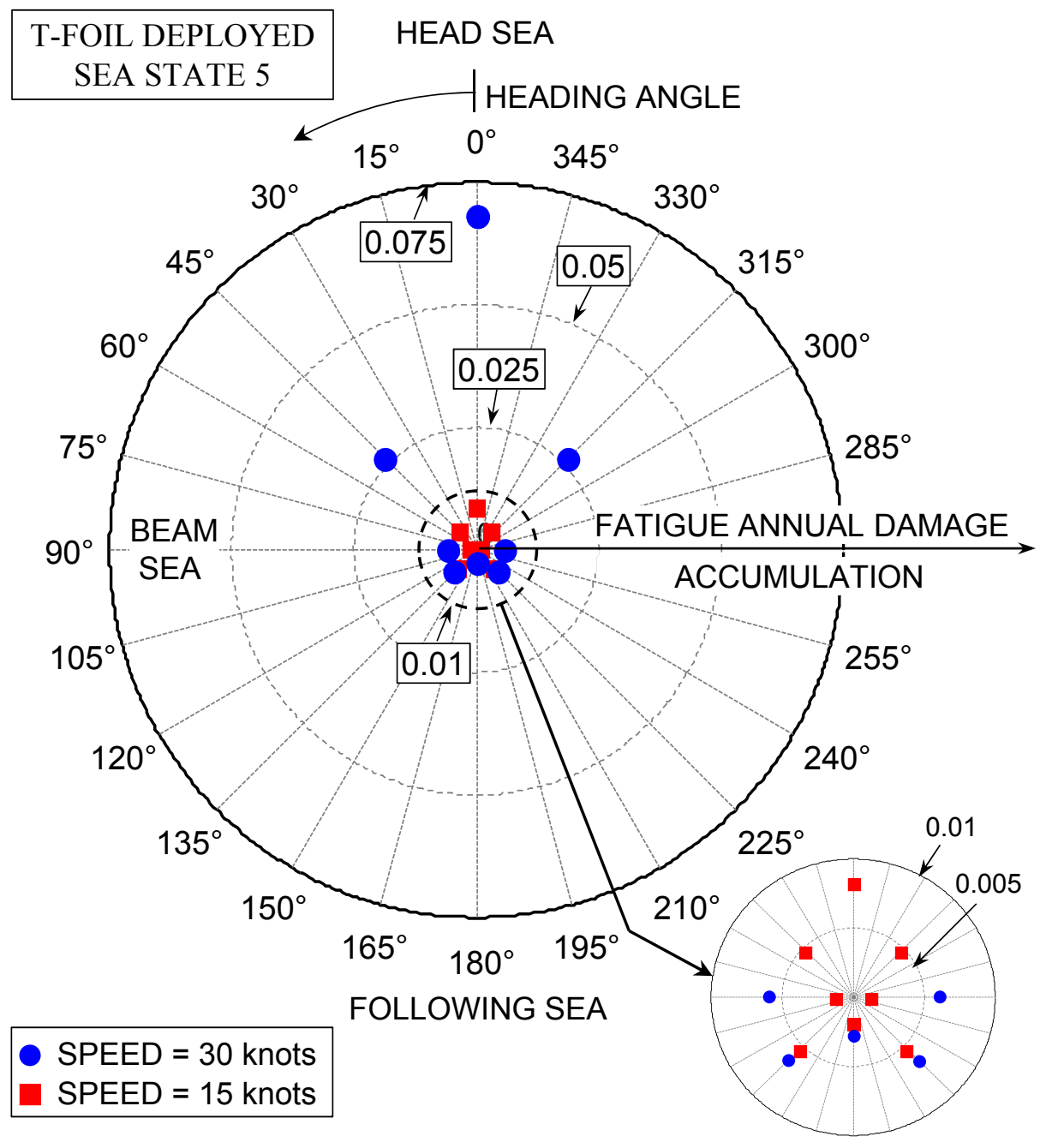

Figure 12 
(a)

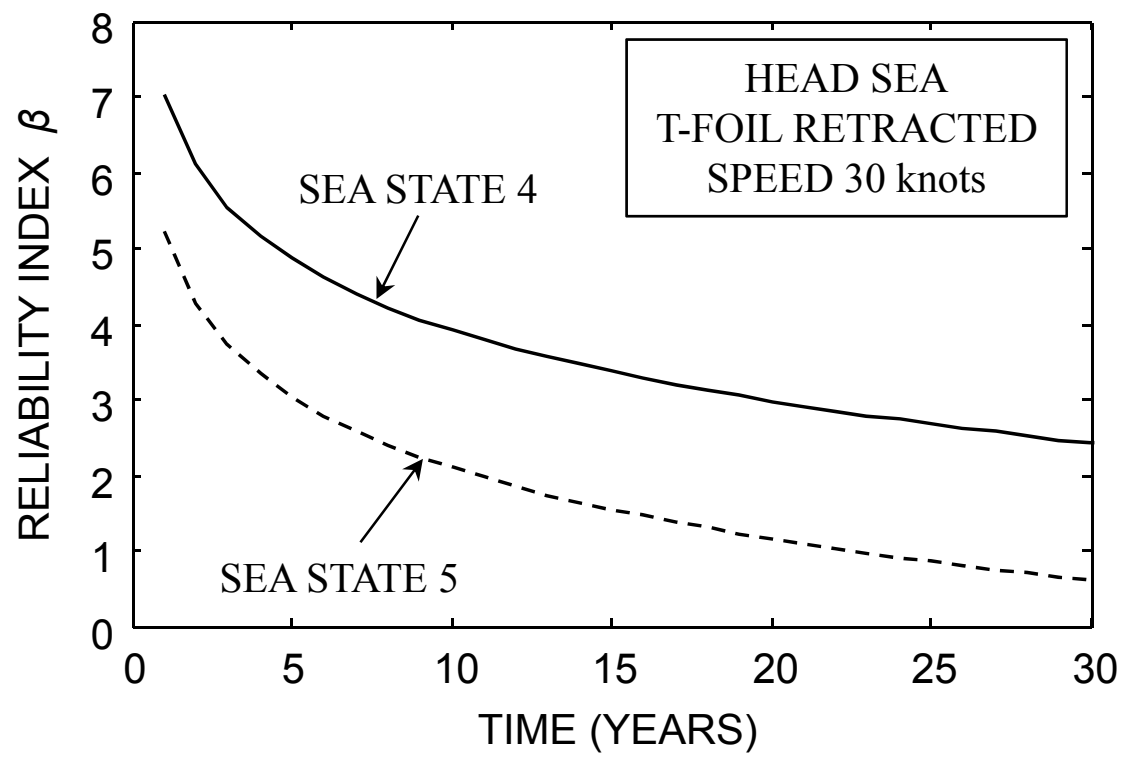

(c)

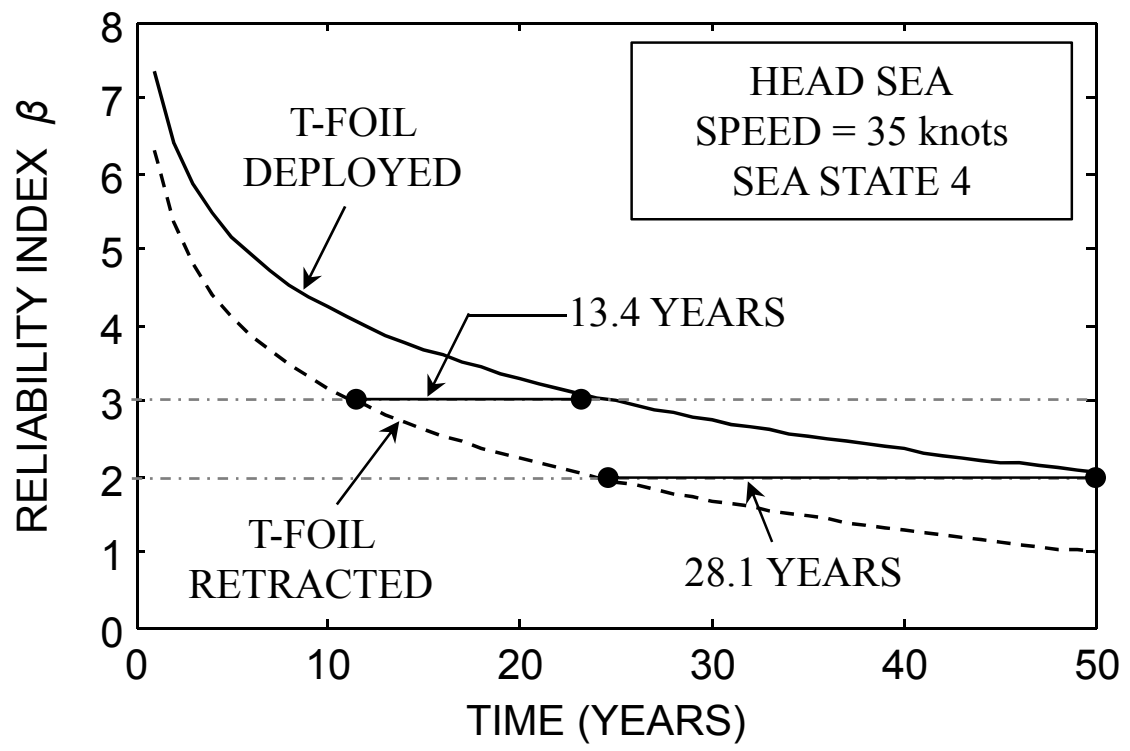

(b)

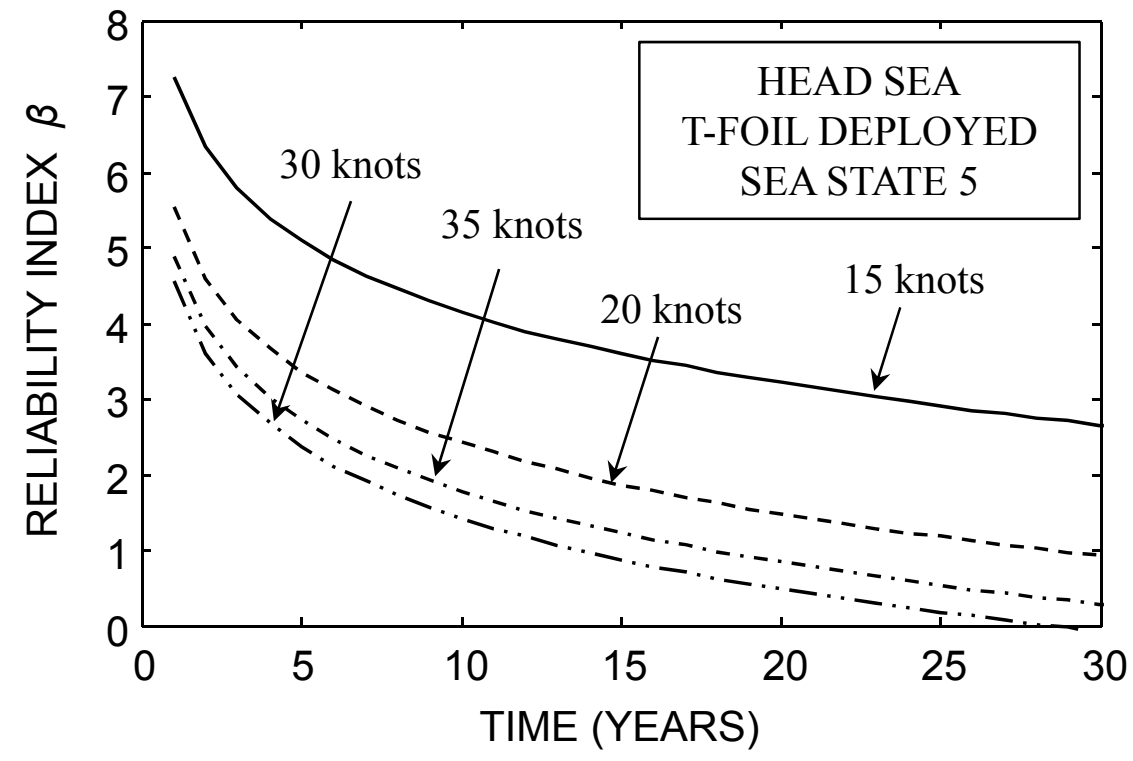

(d)

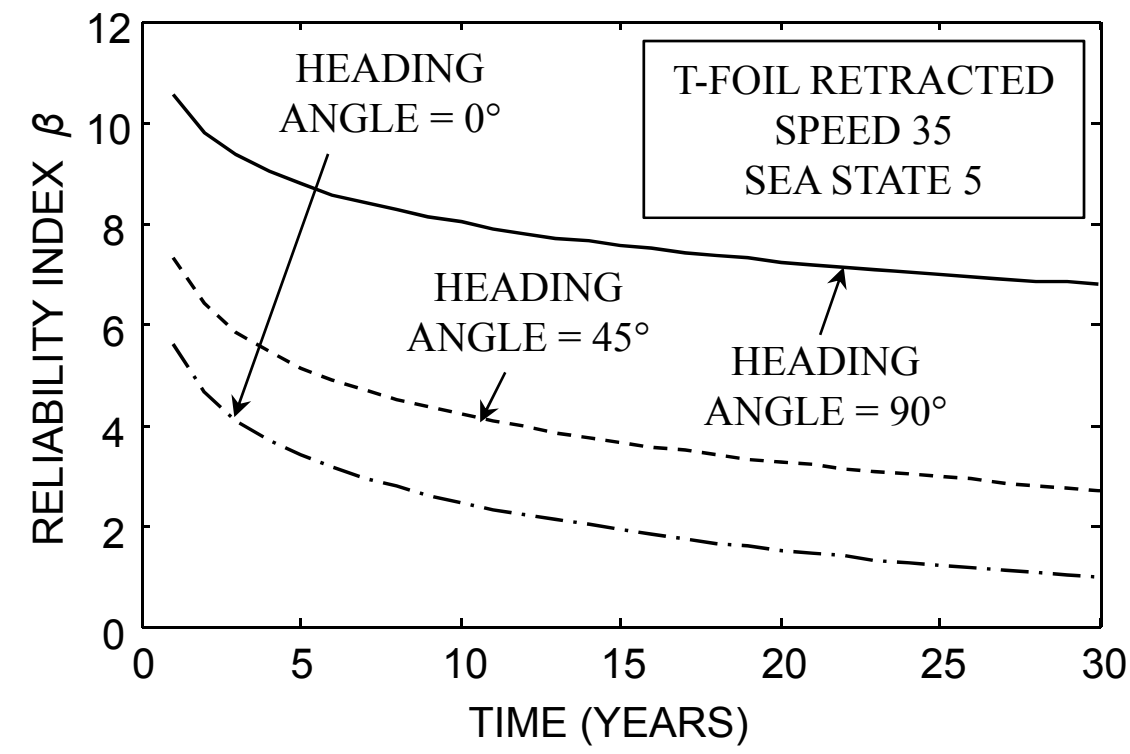

Figure 13 
(a)

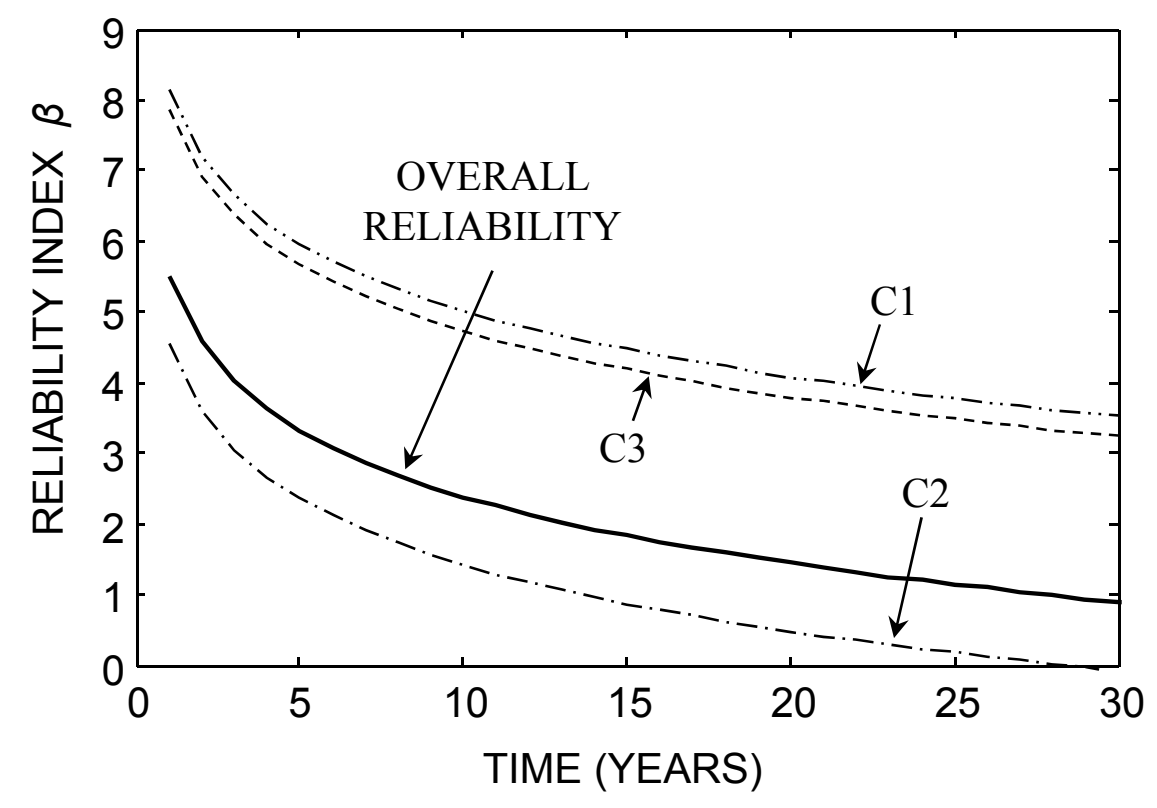

(b)

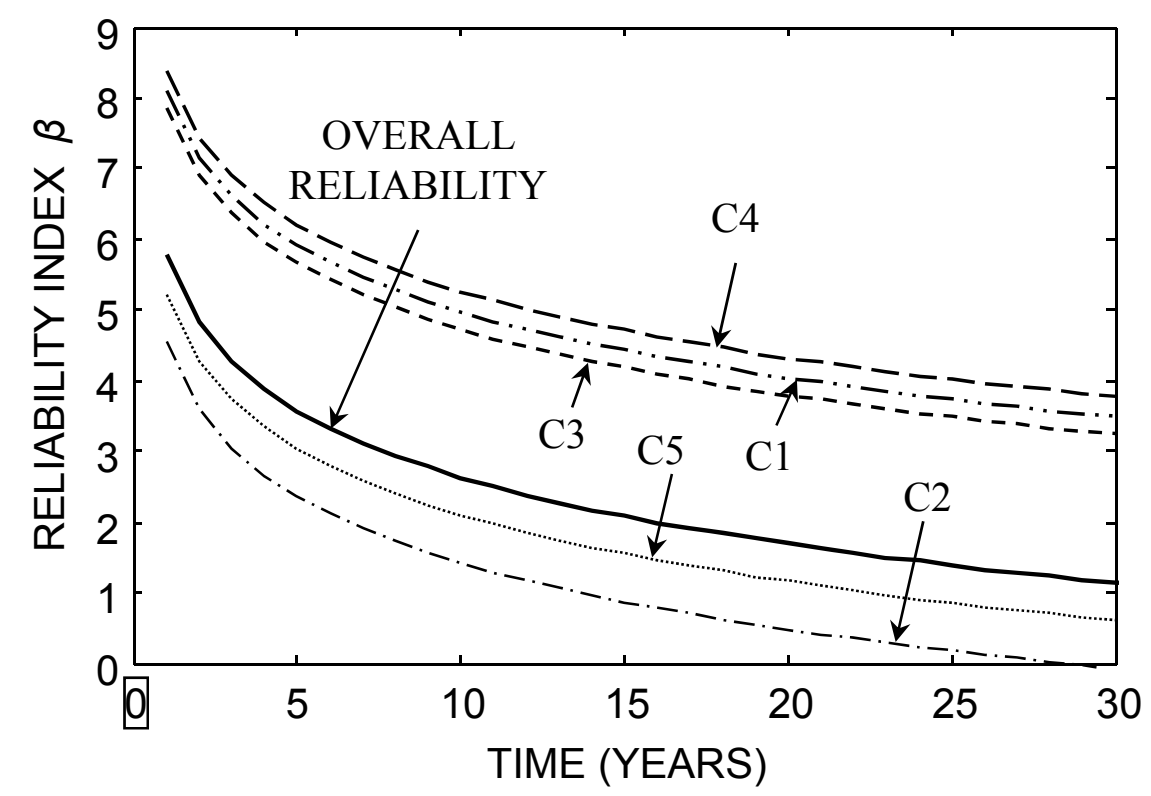

Figure 14 
Table 1. Deterministic parameters and random variables for fatigue assessment

\begin{tabular}{ccccc}
\hline Parameter & Notation & $\begin{array}{c}\text { Distribution } \\
\text { type }\end{array}$ & Mean value & $\mathrm{COV}^{\dagger}$ \\
\hline $\begin{array}{c}\text { Slope of S-N lines } \\
\text { Miner's critical damage } \\
\text { accumulation index } \\
\begin{array}{c}\text { Equivalent constant } \\
\text { amplitude stress range }\end{array}\end{array}$ & $m$ & - & 3.0 & - \\
Intercept, mean value & Lognormal & 1.0 & 0.48 \\
Intercept, lower bound $^{\dagger \dagger}$ & $E(\log A)-2 \times \sigma(\log A)$ & Lognormal & Eq. (4) & 0.1 \\
\hline
\end{tabular}

Coefficient of variation
${ }^{*}$ based on Collette and Incecik 2006
${ }^{*}$ Based on regression analysis of test results for aluminum details reported in Tveiten (1999) 
Table 2. Parameters the first operational profile and the corresponding fatigue life

\begin{tabular}{|c|c|c|c|c|c|c|c|}
\hline \multicolumn{6}{|c|}{ Operational Condition Parameters } & \multicolumn{2}{|c|}{ Fatigue life (years) } \\
\hline $\begin{array}{c}\text { Operational } \\
\text { state }\end{array}$ & Probability & $\begin{array}{l}\text { Sea } \\
\text { State }\end{array}$ & $\begin{array}{l}\text { Heading } \\
\text { Angle }\end{array}$ & $\begin{array}{l}\text { Speed } \\
\text { (knots) }\end{array}$ & T-Foil & $\beta_{\text {target }}=2$ & $\beta_{\text {target }}=3$ \\
\hline $\mathrm{C} 1$ & 0.30 & 5 & $45^{\circ}$ & 15 & Deployed & 90.2 & 43.1 \\
\hline $\mathrm{C} 2$ & 0.45 & 5 & $0^{\circ}$ & 30 & Deployed & 6.55 & 3.13 \\
\hline $\mathrm{C} 3$ & 0.25 & 4 & $315^{\circ}$ & 35 & Deployed & 75.2 & 35.9 \\
\hline
\end{tabular}


Table 3. Parameters the updated operational profile and the corresponding fatigue life

\begin{tabular}{cccccccccc}
\hline \multicolumn{8}{c}{ Operational Condition Parameters } & & \multicolumn{2}{c}{ Fatigue life (years) } \\
\cline { 1 - 3 } $\begin{array}{c}\text { Operational } \\
\text { state }\end{array}$ & Probability & $\begin{array}{c}\text { Sea } \\
\text { State }\end{array}$ & $\begin{array}{c}\text { Heading } \\
\text { Angle }\end{array}$ & $\begin{array}{c}\text { Speed } \\
(\text { knots })\end{array}$ & T-Foil & & $\beta_{\text {target }}=2$ & $\beta_{\text {target }}=3$ \\
\hline C1 & 0.20 & 5 & $45^{\circ}$ & 15 & Deployed & & 90.2 & 43.1 \\
C2 & 0.25 & 5 & $0^{\circ}$ & 30 & Deployed & & 6.55 & 3.13 \\
C3 & 0.20 & 4 & $315^{\circ}$ & 35 & Deployed & & 75.2 & 35.9 \\
C4 & 0.15 & 5 & $45^{\circ}$ & 15 & Retracted & & 97.55 & 46.6 \\
C5 & 0.20 & 5 & $0^{\circ}$ & 30 & Retracted & & 10.76 & 5.15 \\
\hline
\end{tabular}

